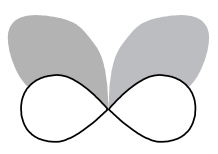

\title{
Ecological biogeography of North American mammals: species density and ecological structure in relation to environmental gradients
}

Catherine Badgley ${ }^{1}$ and David L. Fox ${ }^{2}{ }^{1}$ Museum of Palaeontology, University of Michigan, Ann Arbor, MI 48109, USA, ${ }^{2}$ Department of Earth Sciences, University of California, Santa Cruz, Santa Cruz, CA 95064, USA

\begin{abstract}
Aim To evaluate the relationship of climate and physiography to species density and ecological diversity of North American mammals.

Location North America, including Mexico and Central America.

Methods Species density, size structure and trophic structure of mammalian faunas and nine environmental variables were documented for quadrats covering the entire continent. Spatial autocorrelation of species density and the environmental variables illustrated differences in their spatial structure at the continental scale. We used principal component analysis to reduce the dimensionality of the climatic variables, linear multiple regression to determine which environmental variables best predict species density for the continent and several regions of the continent, and canonical ordination to evaluate how well the environmental variables predict ecological structure of mammalian faunas over North America.
\end{abstract}

Results In the best regression model, five environmental variables, representing seasonal extremes of temperature, annual energy and moisture, and elevation, predicted $88 \%$ of the variation in species density for the whole continent. Among different regions of North America, the environmental variables that predicted species density vary.

Changes in the size and trophic structure of mammalian faunas accompany changes in species density. Redundancy analysis demonstrated that environmental variables representing winter temperature, frostfree period, potential and actual evapotranspiration, and elevation account for $77 \%$ of the variation in ecological structure.

Main conclusions The latitudinal gradient in mammalian species density is strong, but most of it is explained by variation in the environmental variables. Each ecological category peaks in species richness under particular environmental conditions. The changes of greatest magnitude involve the smallest size categories $(<10 \mathrm{~g}, 11-100 \mathrm{~g})$, aerial insectivores and frugivores. Species in these categories, mostly bats, increase along a gradient of decreasing winter temperature and increasing annual moisture and frostfree period, trends correlated with latitude. At the opposite end of this gradient, species in the largest size category (101$1000 \mathrm{~kg})$ increase in frequency. Species in size categories $3(101-1000 \mathrm{~g}), 5(11-100 \mathrm{~kg})$ and $6(101-1000 \mathrm{~kg})$, herbivores, and granivores increase along a longitudinal gradient of increasing annual potential evapotranspiration and elevation.

Much of the spatial pattern is consistent with ecological sorting of species ranges along environmental gradients, but differential rates of speciation and extinction also may have shaped the ecological diversity of extant North American mammals.

\section{Keywords}

Biogeography, climatic gradients, ecological diversity, ecological structure, mammals, North America. 


\section{INTRODUCTION}

Most of the literature about geographical trends in biological diversity has focused on changes in species richness (e.g. Ricklefs \& Schluter, 1993; Huston, 1995; Rosenzweig, 1995). But other aspects of biological diversity also show significant changes over space and time. For example, diversity gradients usually entail changes in the ecological attributes of species assemblages. Study of changes in the kinds of species over environmental gradients should offer greater insights into the causes of diversity gradients than examination of species richness alone.

Here we analyse changes in species richness and ecological diversity of mammals in relation to climatic and physiographical attributes of North America. Faunal and environmental data are compiled on an equal-area grid of quadrat-the same grid used by Simpson (1964) in his classic study of the species density (number of species per quadrat) of North American mammals. Our contribution is valuable partly because it covers all of North America (recent analyses of species richness of North American mammals excluded Mexico and Central America, and thereby omitted the tropical aspects of diversity). Tectonically and geographically, the North American continent has included Mexico and Central America for tens of millions of years. Ecologically, the tropical component of diversity gradients is a critical part of the continental-scale pattern (Brown \& Lomolino, 1998). Also, this paper presents new data about the ecological structure of mammalian faunas in relation to environmental gradients to illustrate how the kinds as well as numbers of mammal species change along environmental gradients.

Our study addresses the following questions: (1) Which environmental variables predict a high proportion of the variation in species density and ecological structure of North American mammals? (2) Does the predictive ability of energy variables and topography, as documented by Currie (1991) and Kerr \& Packer (1997) for Canada and USA, persist when data for the entire continent are analysed? (3) How does the relationship between mammalian species density and environmental variables change in different geographical regions of North America? (4) How does environmental variation influence the kinds as well as numbers of mammal species in North America? (5) Are particular ecological categories of mammals better explained by particular environmental variables?

We assembled information about the current taxonomy of North American mammals, their estimated geographical ranges before European settlement, the size and feeding habits of each species, and quantitative climatic and physiographical variables. Here we evaluate which aspects of ecological structure change the most over environmental gradients, which climatic or physiographical variables predict the greatest changes in ecological structure, and how the major geographical trends in ecological structure relate to changes in species density over the same gradients. Our results indicate clear, often striking changes in ecological structure and species density of mammalian faunas in relation to gradients of climate and physiography.

The ecological variables that form the basis for this study are the size structure and trophic structure of mammalian assemblages. The emphasis on ecological properties of faunal assemblages reflects the view that these properties result from the local environmental accommodation for species of different life habits and resource needs, as well as the evolutionary history of the species and the environmental history of each region. Size structure reflects the physiological and lifehistory variation in each faunal assemblage, as well as the three-dimensional structure of the habitat (e.g. forest vs. grassland; Eisenberg, 1981; Legendre, 1989; McNab, 1990). Trophic structure reflects the range and seasonal availability of food resources exploited by mammals (Eisenberg, 1981). These ecological variables are fairly well documented for extant mammals (and better for North American mammals than for those of other continents) and can be inferred for fossil mammals (e.g. Damuth \& MacFadden, 1990). Thus, our general approach can be linked to studies of climate, evolution and palaeoecology of the North American, Cenozoic, terrestrial fossil record (e.g. Webb, 1989; Stucky, 1990; Janis, 1997).

The environmental variables analysed here include seasonal measures of temperature, annual precipitation, annual evapotranspiration and physiographical complexity, as represented by elevation and relief. The climatic variables reflect the length of the growing season, the annual range of temperature extremes, ambient energy (evapotranspiration) or indicators of primary productivity. The physiographical variables reflect the range of variation in topography and elevational climatic gradients, as well as possible barriers to dispersal. All these variables are potentially relevant to the presence or absence of a particular kind of mammal in a given place.

The spatial units of this study are quadrats measuring 150 miles $(c .240 \mathrm{~km}$ ) on a side. These sampling units are small enough to resolve trends across macroclimatically different regions of North America and large enough to mask the effects of local processes on species composition. This level of spatial resolution depicts geographical (e.g. latitudinal or longitudinal) gradients well but elevational gradients poorly.

This paper is organized as follows. In the next section, we review data and methods, including construction of the faunal database, the sources of data for faunal and environmental variables, and analytical methods used to measure associations among faunal and environmental variables and to predict faunal data from environmental data. Results are presented as regression, ordination and canonical models of the major changes in species density and ecological diversity in relation to environmental conditions across North America and statistical evaluation of these analyses. In the discussion, we summarize major trends and explain how they address the research questions listed above, including comparison with selected results from earlier studies of North American mammals. Finally, we suggest ecological and evolutionary factors that could cause these patterns of mammalian ecological diversity.

\section{DATA AND METHODS}

The data consist of geographical ranges and ecological attributes of mammal species of North America, and climatic and physiographical data from climatic maps, tables and an atlas.

(C) Blackwell Science Ltd 2000, Journal of Biogeography, 27, I437-I467 


\section{Mammal data}

We obtained Simpson's (1964) original data and grid system from the archives of the American Philosophical Society (Philadelphia, PA, USA). For our study, we used the same system of quadrats of $150 \times 150$ miles $=22,500$ square miles, or 58,275 square kilometres (Fig. 1a). We used the mammalian taxonomy of Wilson \& Reeder (1993), the current comprehensive reference for Recent mammals. Simpson's study covered 650 species of noninsular, terrestrial mammals of North America, including bats. The present study includes 721 such species. The difference in species number reflects mainly the elevation of former subspecies to species status and better documentation of species in tropical North America. To document species ranges, we used the geographical-range maps in Hall (1981) whenever possible (e.g. Fig. 1b). For species recognized by Wilson \& Reeder (1993) but not by Hall, we used the relevant subspecies range maps in Hall or species maps from the primary literature. Range maps in Hall (1981) are estimates of species' geographical distributions before extensive European colonization and are based on a high density of sampling localities. For some species (e.g. bison and wolf), the former ranges are much larger than the modern ones. We recorded all species present within each quadrat and constructed species lists for each quadrat. Then we constructed a contour map of species density (Fig. 2) for the entire continent as an update of Simpson's original map. For all the analyses presented below, we omitted coastal quadrats with less than $25 \%$ land area to avoid confounding the influence of area with other influences on species density (Rosenzweig, 1992), for a total of 388 quadrats, unless otherwise indicated.

For each mammal species, supporting ecological data include estimates of body size and trophic status. Body size was recorded as mean adult body weight in grams. Trophic status was recorded as a descriptive term for feeding category and also as a list of food resources. These data were compiled from a variety of sources, including monographs about the mammals of individual localities, states and provinces; field guides; and more general references, such as Nowak (1991). In a few cases, we estimated size or feeding habit from the range documented for a genus, if that range was quite narrow (e.g. much less than an order of magnitude in grams for body weight). For about a dozen species with undocumented body weights, we estimated body weight from a linear regression equation of body weight on head-body length for a documented set of closely related species, typically from the same genus. The main purpose here was to place the species of undocumented body weight into a size category (Table 1). Of the 721 species, reliable data about body weight and trophic habits were recorded for 712, about body size alone for 719 , and about feeding habits alone for 714 species.

Size structure and trophic structure were compiled for the mammalian fauna of each quadrat. Body weight was converted to logarithms (base 10) and size categories were assigned to a full $\log$ unit (Table 1). For trophic structure, we constructed a hierarchical classification of feeding categories, with eight general categories (Table 1), each (with the exception of 'omnivore') subdivided into finer categories. For example, a species recorded as eating mostly fruit and secondarily seeds was assigned to the general category 'frugivore' and to the finer category 'frugivore/granivore.' This study focuses on the distribution of species among the eight general categories.

\section{Climatic and physiographical data}

Table 2 summarizes the meaning and sources of the environmental variables. They include four temperature variables, one precipitation variable, two evapotranspiration variables and two physiographical variables. The temperature variables include annual range of temperature, annual minimum temperature, annual maximum temperature and length of the frostfree period. The annual range of temperature is more strongly influenced by the annual minimum temperature than by the annual maximum temperature. Annual precipitation is strongly determined by the period of maximum rainfall each year. Potential evapotranspiration depicts the maximum water loss due to evaporation and plant transpiration as a function of local meteorology and vegetation, under conditions of unlimited availability of water (Oliver, 1987). Actual evapotranspiration indicates the amount of transpired and evaporated water that results from the water actually available. Potential evapotranspiration (PET) and actual evapotranspiration (AET) are indicators of integrated ambient energy (Currie, 1991). Calculation of PET involves solar radiation, air temperature and moisture content; calculation of AET involves PET and water runoff (evapotranspiration data are based on the Budyko method of calculation; USSR National Committee for the International Hydrological Decade, 1977). Conceptually, these variables are multiplicative interaction terms of radiation, temperature and moisture. Correlations among the climatic variables range from moderate to strong. Elevation and relief are moderately correlated over North America, although they are not highly correlated everywhere (e.g. high plateaus with low relief). Elevation is the average height of a quadrat with respect to sea level, while relief indicates the elevational range within a quadrat. Both variables reflect primarily the geological history of a region.

We used these nine environmental variables for several reasons. First, they all exhibit strong spatial gradients over North America. Second, theory as well as evidence indicate that at least some of these variables limit species' geographical ranges or community structure. Annual variation in temperature strongly influences the seasonal availability of trophic resources and global variation in primary productivity (Cox \& Moore, 1985). A number of mammal species have physiological or behavioural adaptations for unusually cold or warm temperatures. Current geographical-range shifts in some mammals are correlated with regional warming (e.g. Taulman \& Robbins, 1996). We did not include mean annual temperature because the lifecycles of most mammals are more sensitive to seasonal extremes than to mean annual values. The energy variable annual PET has been shown to predict vertebrate species richness well in North America (Currie, 1991), while annual AET is strongly correlated with annual primary productivity (Rosenzweig, 1968). Moisture variables should have a significant effect because of their strong influence on vegetation structure, primary productivity and seasonal availability of 
(a)

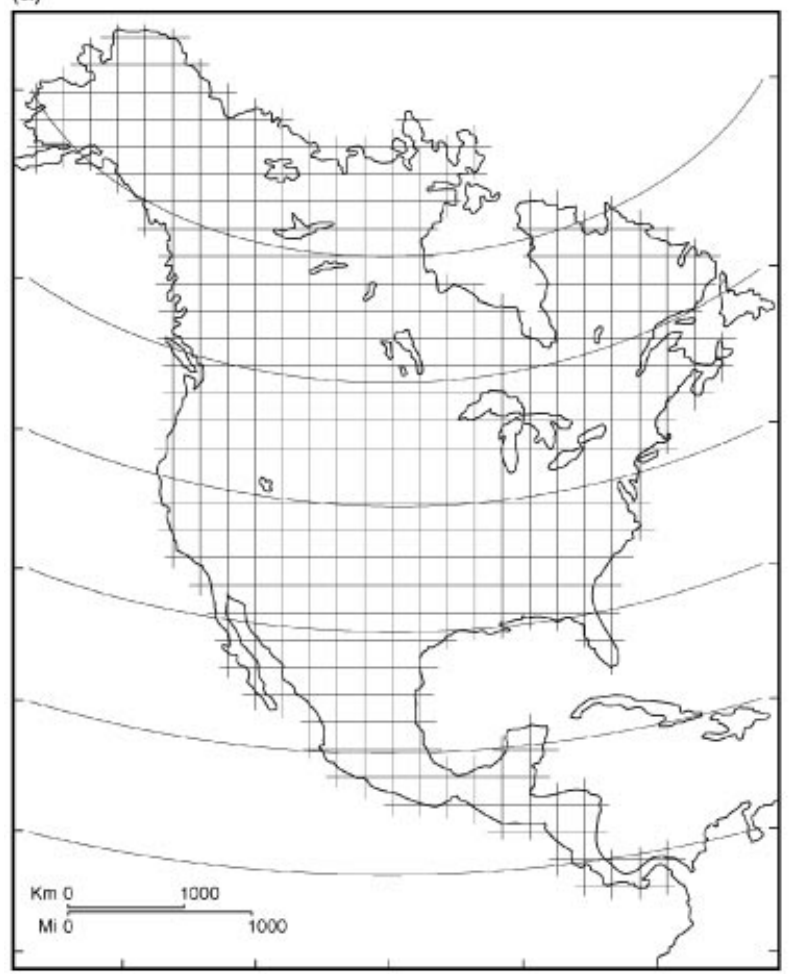

(c)

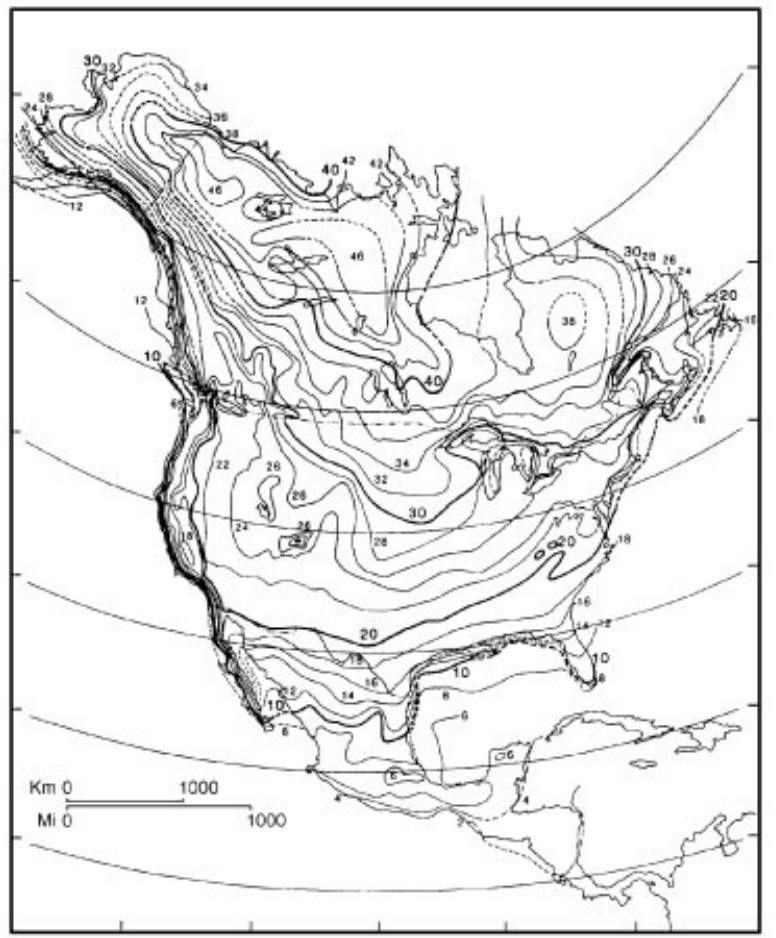

(b)

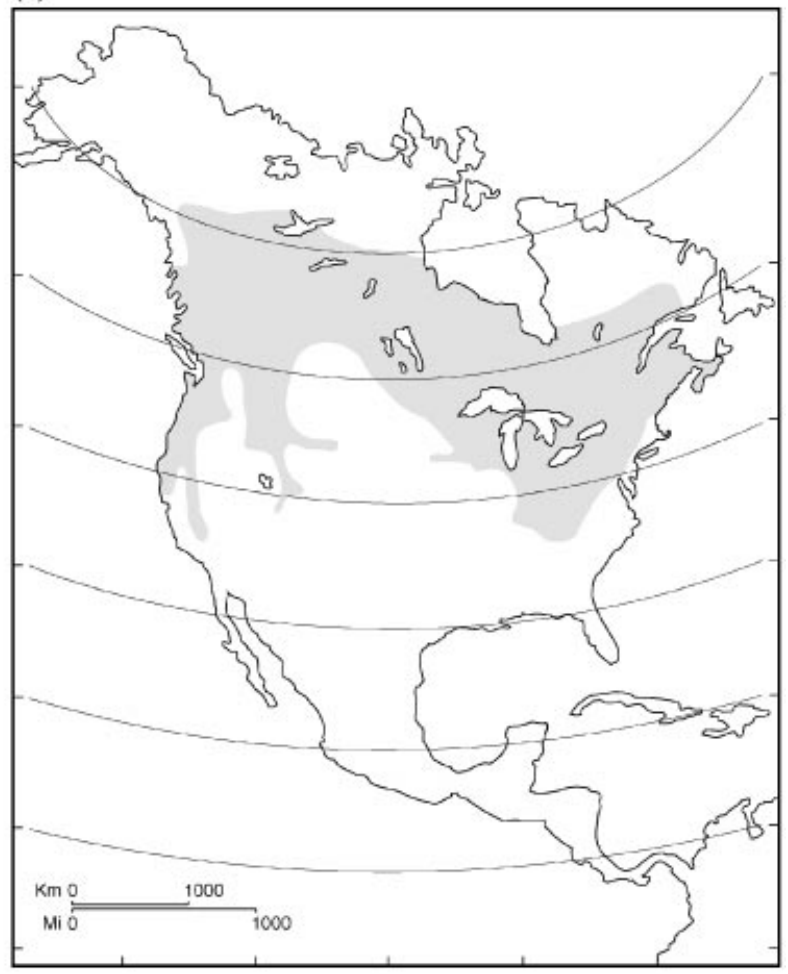

(d)

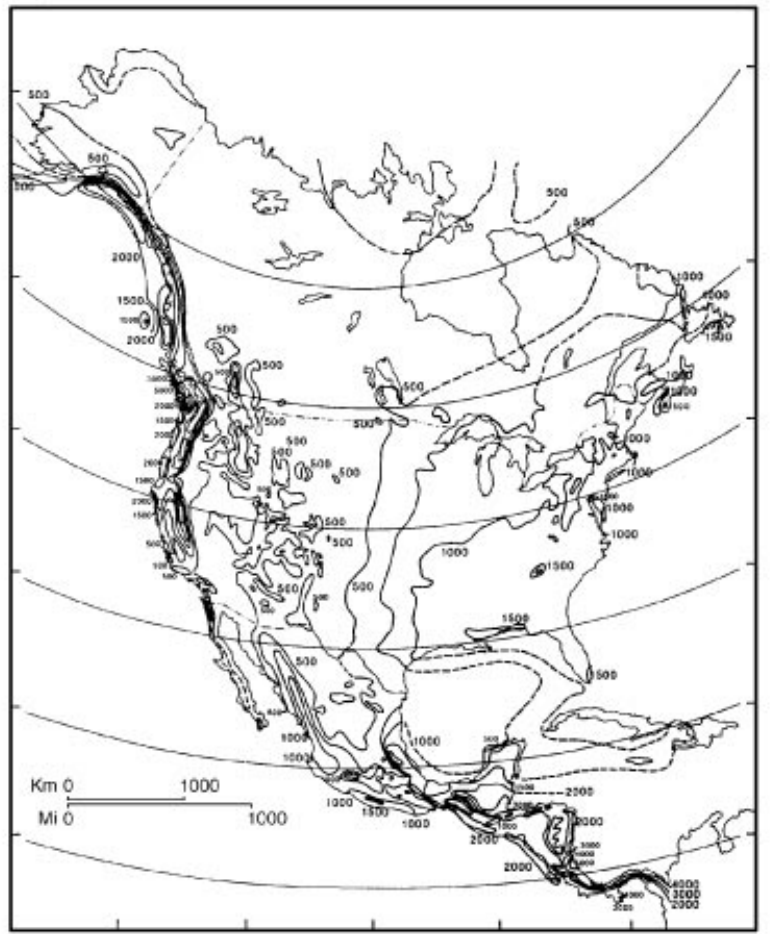

Figure I Primary data for this study include geographical ranges of mammals and climatic data, compiled on a grid system. (a) The grid of quadrats, $150 \times 150$ miles $(242 \times 242 \mathrm{~km})$ on an equal-area projection of North America, was used by Simpson (1964), and is redrawn from his original. (b) Geographical-range map of the fisher, Martes pennanti, redrawn from Hall (1981). The number of species for quadrats in (a) was determined by overlaying the grid on range maps such as (b) for all terrestrial North American mammals. Climatic data were taken from maps such as (c), mean annual range of temperature, and (d), mean annual precipitation, redrawn from Ward et al. (1936). 


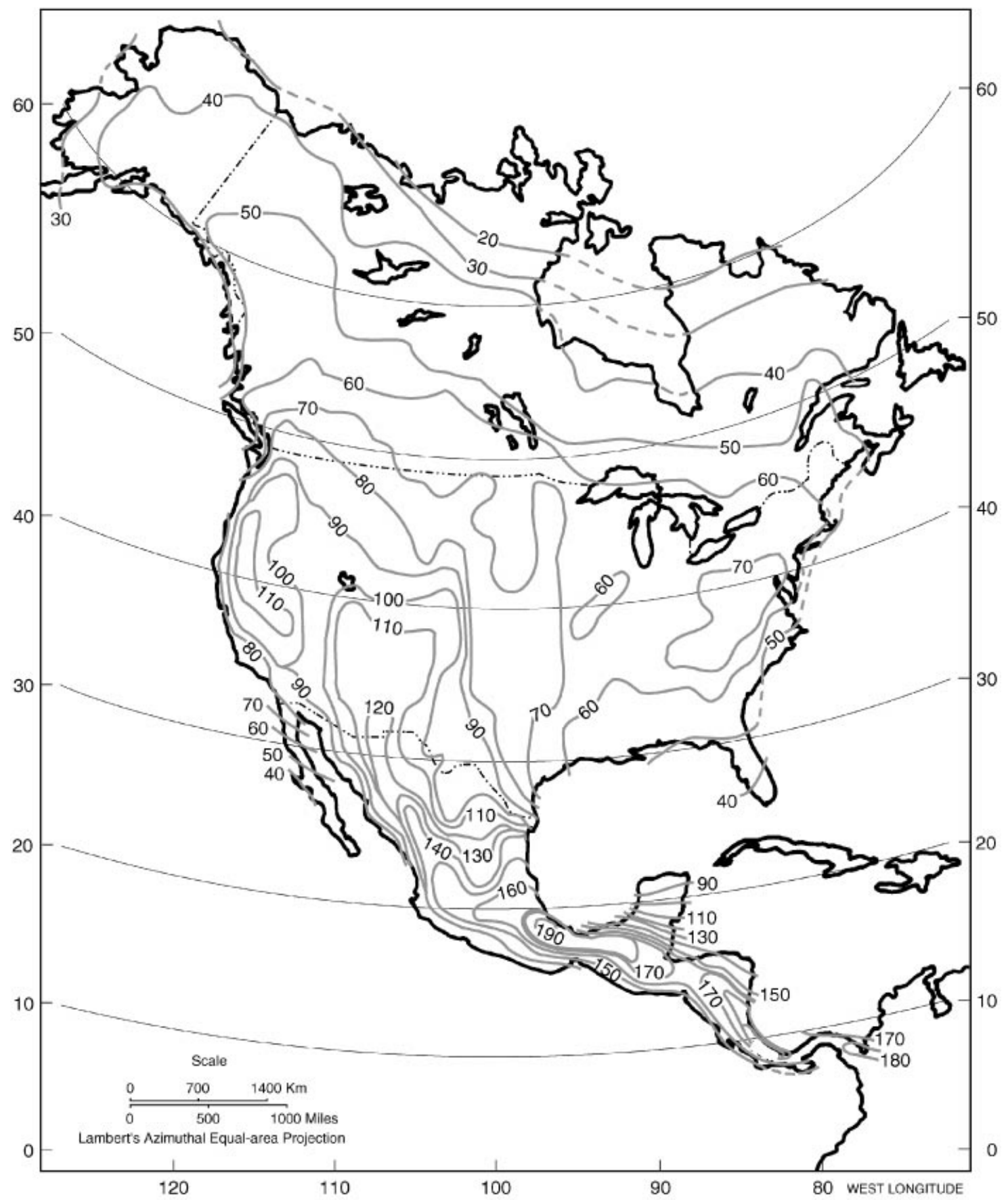

Figure 2 Contour map of mammalian species density (number of species/quadrat), based on the grid system in Fig. 1(a). The contour interval is 10 species. Strong latitudinal, longitudinal and elevational gradients are present, as documented in Fig. 1 from Simpson (1964). See text for further explanation.

plant resources (Whittaker, 1975). Physiographical variables are important because of the vertical stacking of life zones in mountainous regions and, conversely, reduced habitat variation in areas of low relief (Brown \& Lomolino, 1998). Most of these variables (or something similar) have been used in previous studies of environmental controls on species richness, allowing us to compare our results with those from earlier studies. Also, data were available for the entire continent. (We excluded some variables because information was not available over the entire continent.) Latitudinal and longitudinal trends in the environmental variables are shown in Figs 3 and 4.

We collected data for the climatic and physiographical variables in mapped form. Use of contour maps of climatic variables (e.g. Fig. 1c,d), rather than data from individual weather 
Table I Size classes and trophic categories for extant mammals of North America. Abbreviations for trophic categories (in parentheses) are used in some figures.

\begin{tabular}{|c|c|c|}
\hline Size class & Interval & Example \\
\hline 1 & $\leq 10 \mathrm{~g}$ & Pygmy shrew \\
\hline 2 & $11-100 \mathrm{~g}$ & Big brown bat \\
\hline 3 & $101-1000 \mathrm{~g}$ & 13-lined ground squirrel \\
\hline 4 & $1-10 \mathrm{~kg}$ & Red fox \\
\hline 5 & $11-100 \mathrm{~kg}$ & White-tailed deer \\
\hline 6 & $101-1000 \mathrm{~kg}$ & Moose \\
\hline Trophic category & Food resources & Example \\
\hline Aerial insectivore $(\mathrm{AI})$ & Flying insects & Little brown bat \\
\hline Terrestrial invertivore (TI) & Terrestrial arthropods & Short-tailed shrew \\
\hline Aquatic faunivore (AQ) & Aquatic vertebrates, invertebrates & River otter \\
\hline Carnivore $(\mathrm{C})$ & Terrestrial vertebrates & Wolf \\
\hline Frugivore $(\mathrm{F})$ & Fruits, flowers & Jamaican fruit bat \\
\hline Omnivore $(\mathrm{O})$ & Plant and animal foods & Raccoon \\
\hline Granivore (G) & Seeds or nuts & Kangaroo rat \\
\hline Herbivore $(\mathrm{H})$ & Leaves, stems, roots & Mule deer \\
\hline
\end{tabular}

Table 2 Determination and sources of environmental data.

\begin{tabular}{|c|c|c|}
\hline Climatic variable & Determination & Source \\
\hline \multicolumn{3}{|l|}{ Temperature } \\
\hline Mean annual range $\left({ }^{\circ} \mathrm{C}\right)$ & $\begin{array}{l}\text { Difference between month of warmest average } \\
\text { temperature and month with coldest average temperature }\end{array}$ & Ward et al., 1936 \\
\hline Mean annual maximum $\left({ }^{\circ} \mathrm{C}\right)$ & Average of annual maxima over 48 years & Ward et al., 1936 \\
\hline Mean annual minimum $\left({ }^{\circ} \mathrm{C}\right)$ & Average of annual minima over 48 years & Ward et al., 1936 \\
\hline Frostfree period (days) & $\begin{array}{l}\text { Period between last } 0{ }^{\circ} \mathrm{C} \text { in spring and first } \\
0{ }^{\circ} \mathrm{C} \text { in autumn }\end{array}$ & $\begin{array}{l}\text { Ward et al., } 1936 \\
\text { US Department of Commerce, } 1968 \\
\text { Insituto Panamericano de Geografia e Historia, } 1976 \\
\text { Energy, Mines, Resources Canada, } 1981 \\
\text { Universidad Nacional Autónoma de México, } 1991\end{array}$ \\
\hline \multicolumn{3}{|l|}{ Precipitation } \\
\hline \multicolumn{3}{|l|}{ Evapotranspiration } \\
\hline $\begin{array}{l}\text { Potential evapotranspiration } \\
(\mathrm{mm})\end{array}$ & $\begin{array}{l}\text { Maximum moisture loss from transpiration and } \\
\text { evaporation when moisture needs are fully met; Budyko } \\
\text { method, computed for monthly intervals and summed } \\
\text { for annual value }\end{array}$ & $\begin{array}{l}\text { USSR National Committee for the } \\
\text { International Hydrological Decade, } 1977\end{array}$ \\
\hline $\begin{array}{l}\text { Actual evapotranspiration } \\
(\mathrm{mm})\end{array}$ & $\begin{array}{l}\text { Moisture loss from transpiration and evaporation under } \\
\text { actual conditions of moisture supply; Budyko method, } \\
\text { computed from potential evapotranspiration and runoff } \\
\text { for monthly intervals and summed for annual value }\end{array}$ & $\begin{array}{l}\text { USSR National Committee for the } \\
\text { International Hydrological Decade, } 1977\end{array}$ \\
\hline \multicolumn{3}{|l|}{ Physiographical variables } \\
\hline Elevation $(\mathrm{m})$ & $\begin{array}{l}\text { Estimate of average elevation within a quadrat, } \\
\text { weighted by area within each contour interval }\end{array}$ & Anonymous, 1985 \\
\hline Relief (m) & $\begin{array}{l}\text { Difference between highest and lowest elevations } \\
\text { in a quadrat }\end{array}$ & Anonymous, 1985 \\
\hline
\end{tabular}

stations, enabled us to collect climatic data for the same areas and with the same spatial resolution as for the faunal data. For six of the seven climatic variables, we obtained maps for the entire continent. For a seventh variable (length of frostfree period), contour maps were available for Canada and USA, but information for Mexico and Central America was available in a different form (number of days with frost or monthly temperature profiles for selected cities), requiring 
(a) Annual range of temperature

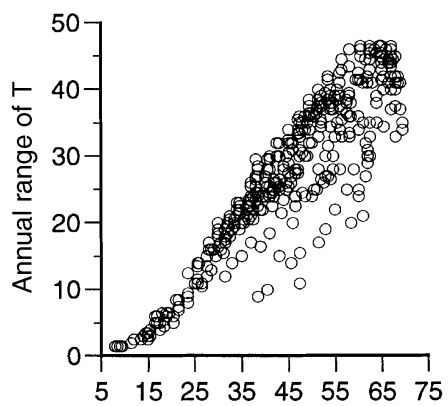

(d) Frostfree period

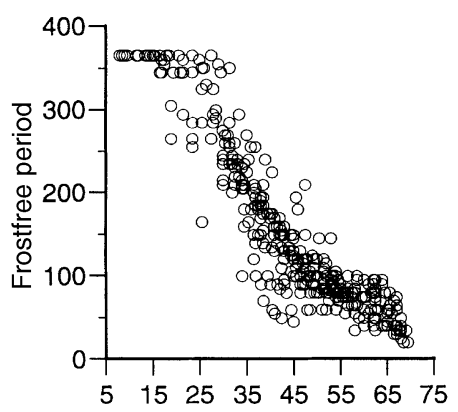

(b) Annual minimum temperature

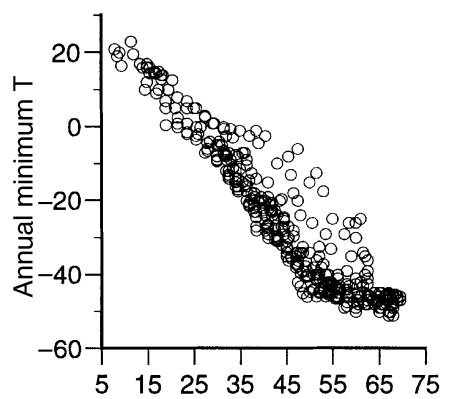

(e) Annual precipitation

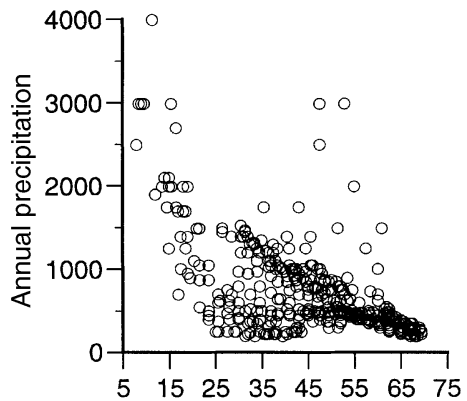

(g) Ann. actual evapotranspiration (h) Topographic relief
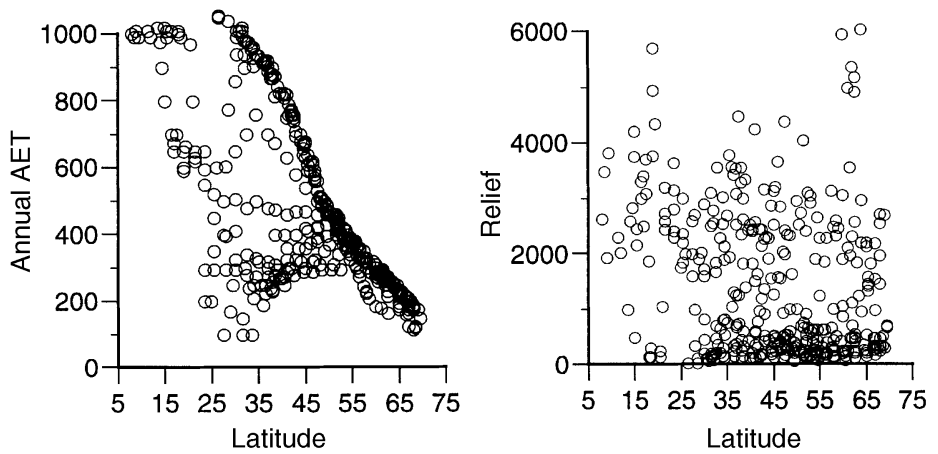

(c) Annual maximum temperature

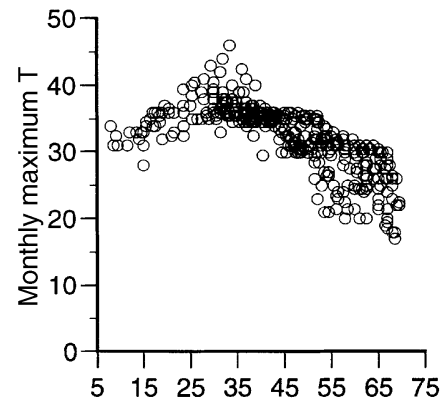

(f) Ann. potential evapotranspiration

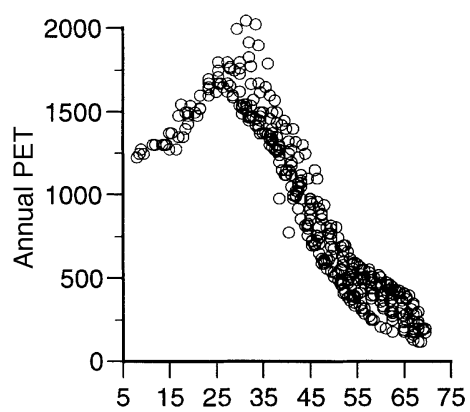

(i) Elevation

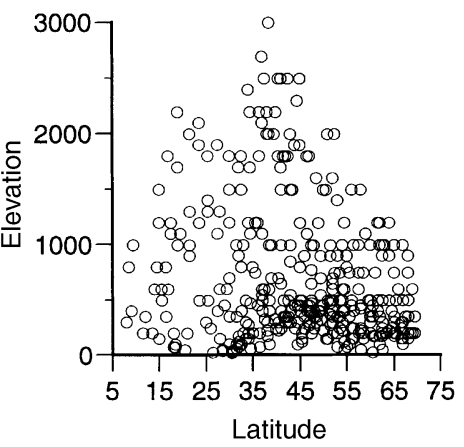

Figure 3 Climatic and physiographical variables for each quadrat $(n=388)$ in relation to latitude, from sources in Table 2 . (a) Annual range of temperature $\left({ }^{\circ} \mathrm{C}\right),(\mathrm{b})$ annual minimum temperature $\left({ }^{\circ} \mathrm{C}\right),(\mathrm{c})$ annual maximum temperature $\left({ }^{\circ} \mathrm{C}\right),(\mathrm{d})$ frostfree period $($ days $)$, (e) annual precipitation $(\mathrm{mm}),(\mathrm{f})$ annual potential evapotranspiration $(\mathrm{mm}),(\mathrm{g})$ annual actual evapotranspiration $(\mathrm{mm})$, (h) relief $(\mathrm{m})$, (i) elevation $(\mathrm{m})$. Some variables show strong latitudinal gradients (e.g. annual range of temperature), while other variables show virtually none (e.g. topographical relief), as expected.

calibration with data from the other sources. For quadrats overlapping the boundary between USA and Mexico, the different kinds of frost data were taken from both sources and a systematic correction was devised to bring the Mexican data close to the values from nearby locations in the USA. This correction was then applied to all quadrats in Mexico. For quadrats in Central American countries, temperature profiles with mean, minimum and maximum monthly temperatures indicated whether any months had frost. We recorded the value of each climatic variable for the centre of each quadrat.
Elevation was estimated visually as the weighted average of height above sea level for each quadrat. This 'average' took into account not only the elevational range but also the area within each contour interval; for quadrats with high relief and large plateaus, this measure was more representative than the midpoint of the elevational range. Relief was measured as the difference between lowest and highest elevations. Both values were estimated from the Times Atlas of the World (Anonymous, 1985) and are considered accurate to within c. $10 \%$. 
(a) Annual range of temperature

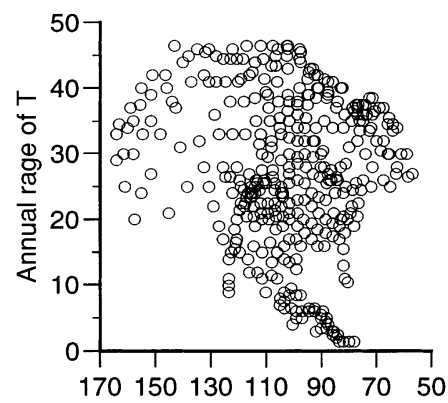

(d) Frostfree period

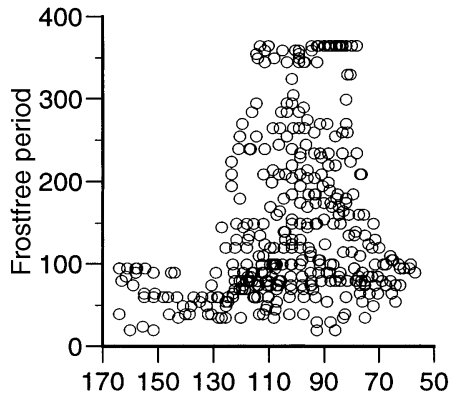

(b) Annual minimum temperature

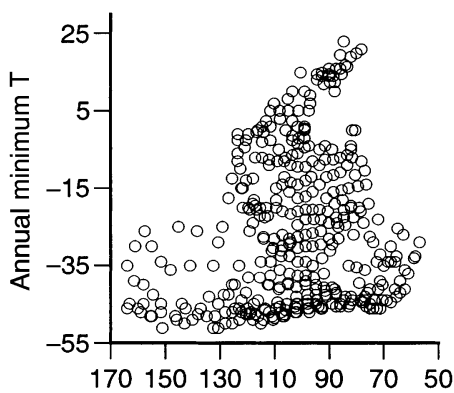

(e) Annual precipitation

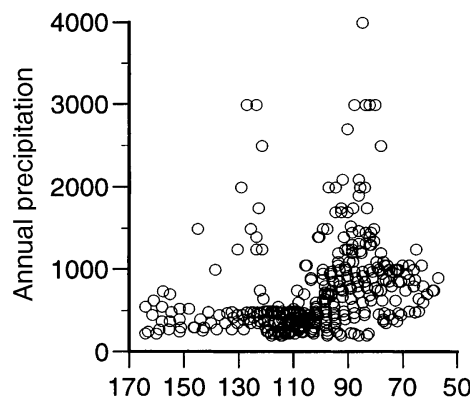

(c) Annual maximum temperature

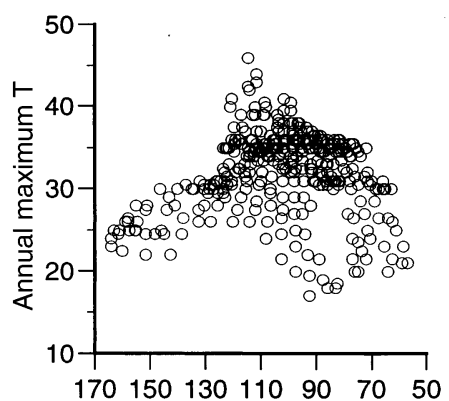

(f) Ann. potential evapotranspiration

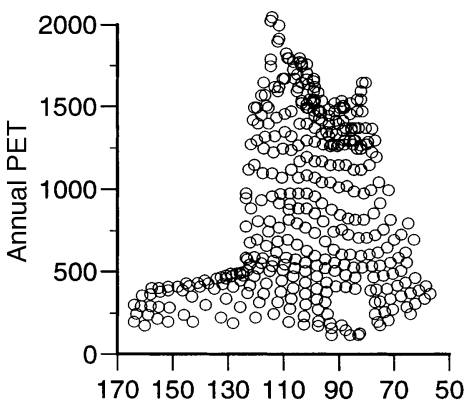

(g) Ann. actual evapotranspiration

(h) Topographic relief

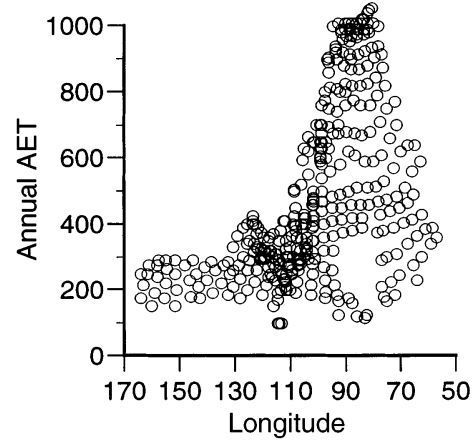

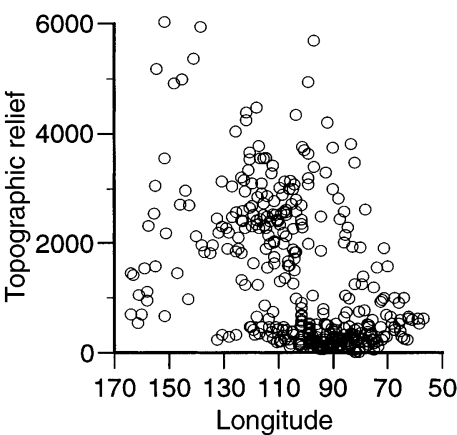

(i) Elevation

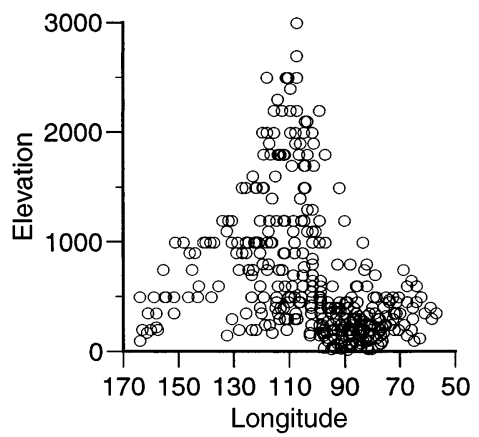

Figure 4 Climatic and physiographical variables for each quadrat $(\mathrm{n}=388)$ in relation to longitude, from sources in Table 2 . Horizontal axis is reversed for ease of interpretation. (a) Annual range of temperature $\left({ }^{\circ} \mathrm{C}\right)$, (b) Annual minimum temperature $\left({ }^{\circ} \mathrm{C}\right),(\mathrm{c})$ annual maximum temperature $\left({ }^{\circ} \mathrm{C}\right),(\mathrm{d})$ frostfree period (days), (e) annual precipitation $(\mathrm{mm}),(\mathrm{f})$ annual potential evapotranspiration $(\mathrm{mm}),(\mathrm{g})$ annual actual evapotranspiration $(\mathrm{mm}),(\mathrm{h})$ relief $(\mathrm{m})$, (i) elevation $(\mathrm{m})$. Most variables show weak east-west gradients.

\section{Methods}

Analytical methods were used to reduce the dimensionality of the environmental data, to identify environmental variables that predict, separately or in combination, a significant fraction of the variation in species density or ecological structure, and to identify which aspects of ecological structure respond most strongly to the major environmental gradients. Methods include spatial autocorrelation analysis, regression analysis, principal component analysis and redundancy analysis.

We evaluated spatial autocorrelation for all environmental variables and species density. The statistic is Moran's I, calculated for nine classes of equal distance (Sokal \& Thomson, 1987). Due to memory limitations of the software (Spatial
Autocorrelation Analysis Program; Wartenberg, 1989), we had to restrict our sample to 360 quadrats; we withheld 28 quadrats with $>50 \%$ of the area in water from around the continental margin, so that no regions were selectively reduced. The resulting correlograms (Fig. 5, Table 3) indicate similarities and differences in the spatial structure of variables at the continental scale.

We used linear multiple regression to determine which of the environmental variables has a statistically significant, unique contribution to the prediction of species density (Tables 4 and 5). Data were log-transformed for all variables to stabilize their variances (Sokal \& Rohlf, 1981). We compared different regression models with subsets of the nine environmental variables, using nested F-tests (Weisberg, 1985; Gujarati, 1995), to determine 
a regression model that was both ecologically meaningful and statistically sound (Appendix 1 has results of nested F-tests). We computed regression equations for all quadrats and for regional subsets of North America to determine how regression models differ among different geographical regions (Table 6). Then we examined the residuals of the regression for all quadrats in relation to latitude to see if any variance unexplained by the regression was correlated with latitude (Fig. 6).

To reduce the dimensionality of the climatic variables, we performed a principal component analysis of the climatic data for all quadrats (Fig. 7, Table 7). For this analysis, we used the correlation matrix since some of the variables were measured in different units. Also, we plotted the frequency of species among the six size classes and eight trophic categories in relation to the first two principal components summarizing the climatic variables. These graphs illustrate the major changes in each ecological category of mammalian faunas along an environmental temperature gradient (principal component 1, Fig. 8) and a moisture gradient (principal component 2, Fig. 9).

Finally, we used a form of canonical analysis to evaluate the relationship between faunal variables and environmental variables simultaneously. Among canonical methods, we chose redundancy analysis, the canonical form of principal component analysis (Gittins, 1985). Redundancy analysis is a method of direct gradient analysis (since environmental data play an active role in the ordination), similar to canonical correlation analysis in assuming a model of linear response of one set of variables to the other set. Redundancy analysis combines ordination and multiple regression to maximize the "predictable variance' that each set of variables extracts from the other set (Gittins, 1985). But the relationship between the two sets of variables is non-symmetrical: one set is designated as the predictor variables and the other set as the response variables, rather than each set predicting the other, as in canonical correlation analysis. Here the environmental variables were designated as predictors and the faunal variables as responses. We used untransformed values of species density in each of the size and trophic categories; faunal variables were centred but not standardized (so the ordination of faunal variables was performed on a covariance matrix); environmental variables were both log-transformed and standardized before analysis. Canonical analyses were performed with the software CANOCO (version 4, ter Braak \& Smilauer, 1998).

As a prelude to the redundancy analyses, we examined the relationship between each environmental variable individually and all faunal variables. Table 8 a lists the $R^{2}$ (coefficient of determination) from regression of the faunal variables on each environmental variable to compare the variance in the faunal data explained by each environmental variable alone. Since some of the environmental variables are highly correlated with each other, it was not likely that all of them would make a significant and unique contribution to the redundancy analysis of faunal and environmental variables. The 'forward selection of environmental variables' (Table $8 \mathrm{~b}$ ) in CANOcO allowed selective addition of environmental variables to a canonical analysis (ter Braak \& Smilauer, 1998). The first variable explained the greatest variation in the faunal data; the next variable explained the greatest variance in combination with the first, etc.
Before each variable was added, the significance (at $P \leq 0.01$ ) of its contribution to the $R^{2}$ of the $F$-ratio was calculated (see Appendix 1).

In addition, we used the variance inflation factor (reciprocal of tolerance) of each variable to indicate when excessively high correlation (multicollinearity) among environmental variables was present. The variance inflation factor is a function of the partial correlation between each variable and the other independent variables in the analysis. When this factor is high for a particular variable, it means that it is so highly correlated with one or more other independent variables as to make virtually no unique contribution to the regression analysis (Montgomery \& Peck, 1982; ter Braak \& Smilauer, 1998). We used both the forward selection of environmental variables and their variance inflation factors to select a subset of the nine environmental variables that explains a high fraction of the variance in the faunal data, lacks high multicollinearity and represents an ecologically meaningful combination.

Following these criteria, we present summary results and ordination diagrams for two redundancy analyses (Tables 9 and 10, Fig. 10). These include an analysis using all faunal and environmental variables (Fig. 10a,b) for heuristic purposes and a better analysis with all faunal variables in relation to five environmental variables (Fig. 10c,d). For the better redundancy analysis, a redundancy index for each faunal variable is given in Table 11. The original faunal data in each size and trophic category are plotted in the ordination space of the better redundancy analysis (Figs $11 \& 12$ ). For comparison, species density is also plotted in this ordination space (Fig. 11g), although it is not included in the redundancy analysis.

\section{RESULTS}

The results are presented in seven parts: (1) The species density of North American mammals is summarized in the contour map of Fig. 2. (2) Geographical trends in environmental variables are illustrated graphically, followed by (3) spatial autocorrelation analysis of the environmental variables and species density. (4) Regression of species density on the environmental variables indicates which variables contribute to the prediction of species density for all of North America and for several geographical regions of the continent. (5) Climatic data are summarized in a principal component analysis, which reduced most of the variance in the climatic data to two axes. (6) Rather than plot each faunal variable in relation to each climatic variable separately, we plotted each faunal variable in relation to the first two principal component axes based on climatic variables. (7) Two redundancy analyses illustrate how environmental and faunal variables covary simultaneously and which environmental variables effectively predict the variation in ecological structure of mammalian faunas.

\section{(I) Geographical trends in species density}

We tabulated species density for all quadrats and plotted isolines of species density. The resulting map (Fig. 2) preserves the major trends documented by Simpson (see Fig. 1 in Simpson, 
1964). These include a strong latitudinal gradient, with the lowest values of species density in north-central Canada and the highest values in montane Central America; contours running predominantly east-west over Canada; contours generally following changes in elevation south of $c .50^{\circ} \mathrm{N}$; local plateaus of species density in the Appalachians, the Sierra Nevada Mountains of California, the southern highlands of Mexico, Nicaragua and Costa Rica; and diminished species richness in peninsular areas (e.g. Baja California and Florida) relative to mainland regions at the same latitude. Minor details of the two maps differ. The present map reflects higher values of species density in almost every quadrat, with a proportionally greater increase in the quadrats of Central America. These differences reflect changes in mammalian taxonomy and more detailed documentation of species ranges in subtropical and tropical regions of North America. Simpson's map contains a closed plateau of high values in the Rocky Mountains and Colorado Plateau, whereas Fig. 2 shows high species density in this area as part of a trend extending southward into the Cordilleran ranges of Mexico. The small, mid-continental valley in species density (values of 60-65) in Simpson's map is displaced slightly to the south-east in Fig. 2. Currie's contour map of mammalian species density (Fig. 1b from Currie, 1991) has lower values of species density throughout Canada and the USA, compared with Simpson's map or Fig. 2 here, but the general trends with latitude, longitude, and elevation are similar.

Much of the variation in species density across North America results from changes in the number of species of Rodentia (rodents) or Chiroptera (bats) - an observation of no great surprise because together they comprise over half of all living species of mammals (Wilson \& Reeder, 1993). Among the nine mammalian orders that encompass all the terrestrial and semiaquatic species of North America, most of the change in species density from north to south occurs in bats and rodents (ordinal data not presented here). The species density of insectivores, carnivores, artiodactyls and lagomorphs shows much less change and subtle, if any, latitudinal trends. Species in the remaining four orders (didelphimorphs, xenarthrans, primates and perissodactyls) occur mainly in tropical to subtropical North America at consistently low densities. From east to west, the most striking changes in species density occur in rodents.

\section{(2) Geographical trends in environmental variables}

Figures 3 and 4 illustrate the climatic and physiographical variables in relation to latitude and longitude, respectively. These graphs depict general trends for each environmental variable and show which variables have similar trends. While latitude and longitude are not the only important geographical orientations, they are both significant in North America because of the orientation of major mountain ranges and coastlines; also, the annual distribution of solar insolation varies systematically with latitude.

Several of the climatic variables show strong gradients with latitude (Fig. 3). Annual range of temperature (Fig. 3a), annual minimum temperature (Fig. 3b), and frostfree period (Fig. 3d) have fairly tight monotonic trends. Annual maximum temper- ature has a unimodal trend with a smaller range of overall variation than in the other temperature variables (Fig. 3c). Annual precipitation generally declines with increasing latitude, and the trend is quite noisy (Fig. 3e). Annual PET has a unimodal pattern, with the highest values occurring between 25 and $35^{\circ} \mathrm{N}$, and is truncated below $5^{\circ} \mathrm{N}$ (Fig. 3f). Annual AET declines with increasing latitude; it has a smooth upper bound with considerable variation below the bound (Fig. 3h). Neither topographical relief nor elevation shows a strong relationship with latitude (Fig. 3i,j). Most climatic variables show a strong relationship with latitude because the processes that drive the global climate system have strong gradients from the equator to the poles.

In contrast, the environmental variables have weak trends with longitude (Fig. 4). Quadrats west of $130^{\circ} \mathrm{W}$ are from northwestern British Columbia, the Yukon territory and Alaska, and all lie north of $55^{\circ} \mathrm{N}$. These quadrats form a cohesive left tail in some of these graphs. Annual range of temperature, annual minimum temperature and frostfree period show no trend in relation to longitude except for reduced variation in quadrats west of $130^{\circ} \mathrm{W}$ (Fig. 4a,b,d). Annual maximum temperature shows a noisy, unimodal pattern with the highest values between 110 and $120^{\circ} \mathrm{W}$ (Fig. 4c). Annual precipitation has a weak positive trend with considerable variation (Fig. 4e). Annual PET reaches maximum values in western North America at lower latitudes, with very low values in the high-latitude northwestern quadrats (Fig. 4f). Annual AET reaches maximum values in eastern North America, with a tail of low values in the high-latitude north-western sites (Fig. 4g). Relief is generally greater in western North America, including the northwestern quadrats (Fig. 4h). Elevation is generally higher for quadrats west of $100^{\circ} \mathrm{W}$, with the highest values through the Rocky Mountain region around $110^{\circ} \mathrm{W}$ longitude (Fig. $4 \mathrm{i}$ ).

\section{(3) Spatial autocorrelation}

Spatial autocorrelation analysis measures the spatial structure in a dataset over all directions simultaneously (Sokal \& Oden, 1978; Sokal \& Thomson, 1987). Moran's I-statistic expresses the correlation among values of a variable in relation to the distance separating localities. Positive autocorrelation implies similarity of values for the specified distance; negative autocorrelation implies dissimilarity of values for that distance. The correlogram is a graph of the autocorrelation statistic in relation to distance. Moran's I was calculated for nine equaldistance classes of about $1000 \mathrm{~km}$ in width (Fig. 5) for the environmental variables (Fig. $5 \mathrm{a}-\mathrm{c}$ ) and species density (Fig. $5 \mathrm{~d}$ ). Table 3 lists the distance classes and the number of quadrat pairs in each, and indicates whether $I$ for each variable is statistically significant in each distance class.

Correlograms for the four temperature variables are plotted together in Fig. 5(a). All four variables show high to moderate, positive spatial autocorrelation over distances up to $c .3000 \mathrm{~km}$ and significant negative autocorrelation above 3000 and below $8000 \mathrm{~km}$. Annual maximum temperature and annual range of temperature show slightly increasing values of $I$ over the greatest distances, whereas annual minimum temperature and frostfree period have monotonically 
(a)

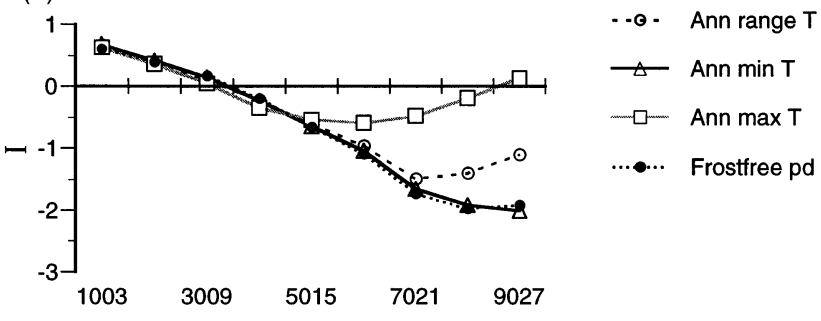

(b)

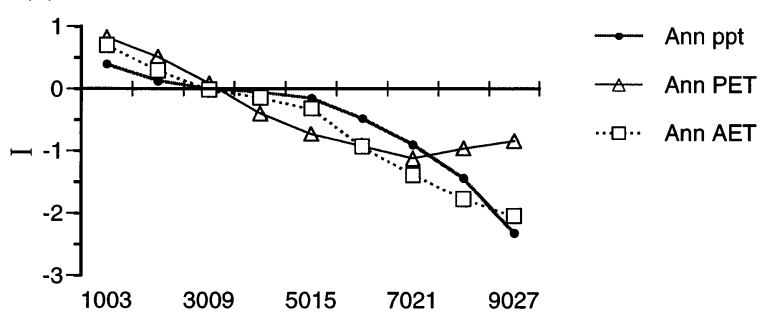

(c)

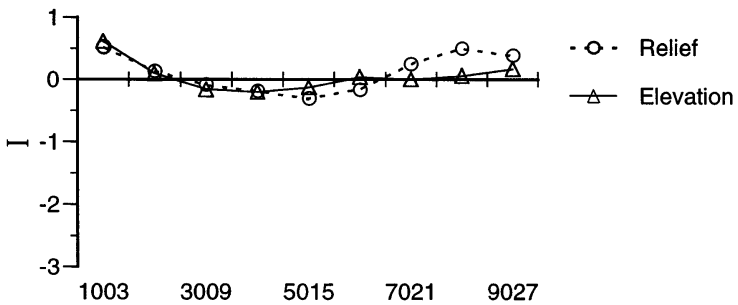

(d)

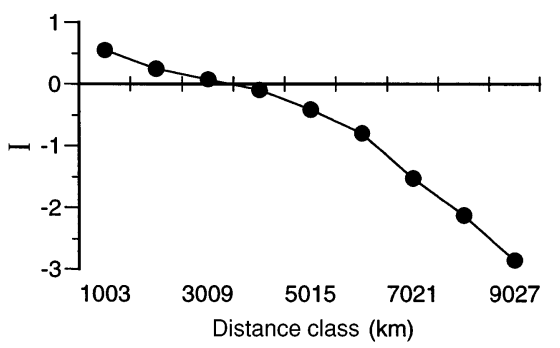

Figure 5 Correlograms (from spatial autocorrelation analysis) for environmental variables and species density $(n=360)$. Moran's $I$-statistic is plotted for nine equal-distance classes (see Table 3 ) in each correlogram. (a) Four temperature $(\mathrm{T})$ variables: annual range of temperature, annual minimum temperature, annual maximum temperature and frostfree period. (b) Precipitation (ppt) and evapotranspiration variables: annual precipitation, annual potential evapotranspiration (Ann PET) and annual actual evapotranspiration (Ann AET). (c) Two physiographical variables: relief and elevation. (d) Species density. See text for explanation.

declining relationships that reach an asymptote at about $9000 \mathrm{~km}$. Correlograms for annual precipitation and the evapotranspiration variables (Fig. 5b) show moderate to high positive autocorrelation over distances up to $c .3000 \mathrm{~km}$. Over larger distance classes, annual precipitation and annual
AET show high negative autocorrelation. Annual PET is fairly similar to the other two variables to $c .3000 \mathrm{~km}$; its values of $I$ increase slightly at greater distances, similar to the pattern for annual maximum temperature (Fig. 5a). The physiographical variables (Fig. 5c) show positive autocorrelation over short distances, low negative autocorrelation over intermediate distances and positive autocorrelation over the greatest distances. The correlogram for species density (Fig. 5d) indicates significant positive autocorrelation up to $c .3000 \mathrm{~km}$, then rapidly declining negative autocorrelation over larger distance classes. The correlogram for species density most closely resembles those of annual minimum temperature and frostfree period (Fig. 5a) up to $c .7000 \mathrm{~km}$ and that of annual precipitation (Fig. 5b) at greater distances. The monotonically declining pattern of several variables is characteristic of a cline (Sokal \& Oden, 1978).

\section{(4) Regression of species density on environmental variables}

We used linear multiple regression of species density on the environmental variables to evaluate how well they could predict species density and to determine which subset of environmental variables would best predict species density by ecological and statistical criteria. We log-transformed all the variables before analysis. Hence, the regression equations express proportional change in species density as a function of proportional change in environmental variables.

A satisfactory regression model is theoretically meaningful, has a low standard error of regression, lacks high multicollinearity of independent variables and has significant coefficients for the independent variables, as well as other properties (Gujarati, 1995). The full model, using all nine environmental variables, has the highest $R^{2}$ value and lowest standard error, but some of the coefficients are not significant (at $P=0.05$ ) and there is high multicollinearity for several variables. To determine a more satisfactory regression model with fewer independent variables, we omitted variables singly or in combination and compared each reduced regression model to the full model via a nested $F$-test. This test compares the effect of different models (with the same dependent variable in the same units) on the sum of squared errors (SSE; Gujarati, 1995). We first tested whether all the temperature variables, all the moisture variables, and both topography variables were each significant as a group to the regression. Each group was significant (i.e. its omission caused a significant increase in the SSE relative to the full model). Next, within each group, we calculated the auxiliary $R^{2}$ of each variable with the other variables in the group. (The auxiliary $R^{2}$ expresses the proportion of variance of an independent variable shared with the other independent variables.) For variables with a high auxiliary $R^{2}$, we omitted one or more variables from the group and recalculated the auxiliary $R^{2}$. We selected from each group a meaningful set of variables that were not highly correlated with other variables included from the same group. This process resulted in several possible reduced regression models. We compared each of these to the full model using the nested $F$ test and thereby arrived at the models reported in Table 4. 
Table 3 Distance classes used in spatial autocorrelation analysis and the statistical significance of Moran's $I$ for each variable plotted in Fig. 5 and for the residuals from the multiple regression in Fig. 6(b). Nine distance classes, each approximately $1000 \mathrm{~km}$ in width, were used; the number of quadrat pairs varies among distance classes. ( $n=360$ quadrats; see text for explanation).

\begin{tabular}{|c|c|c|c|c|c|c|c|c|c|}
\hline Distance class & 1 & 2 & 3 & 4 & 5 & 6 & 7 & 8 & 9 \\
\hline Upper distance boundary $(\mathrm{km})$ & 1003 & 2006 & 3009 & 4012 & 5015 & 6018 & 7021 & 8024 & 9027 \\
\hline No. quadrat pairs per class & 7063 & 15,416 & 16,977 & 13,133 & 7362 & 3232 & 969 & 367 & 101 \\
\hline Annual range temperature & $* *$ & $* *$ & $* *$ & $* *$ & $* *$ & $* *$ & $* *$ & $* *$ & $* *$ \\
\hline Annual minimum temperature & $* *$ & $* *$ & $* *$ & $* *$ & $* *$ & $* *$ & $* *$ & $* *$ & $* *$ \\
\hline Annual maximum temperature & $* *$ & $* *$ & $* *$ & $* *$ & $* *$ & $* *$ & $* *$ & $* *$ & $* *$ \\
\hline Frostfree period & $* *$ & $* *$ & $* *$ & $* *$ & $* *$ & $* *$ & $* *$ & $* *$ & $* *$ \\
\hline Annual precipitation & $* *$ & $* *$ & NS & $* *$ & $* *$ & $* *$ & $* *$ & $* *$ & $* *$ \\
\hline Annual PET & $* *$ & $* *$ & $* *$ & $* *$ & $* *$ & $* *$ & $* *$ & $* *$ & $* *$ \\
\hline Annual AET & $* *$ & $* *$ & NS & $* *$ & $* *$ & $* *$ & $* *$ & $* *$ & $* *$ \\
\hline Relief & $* *$ & $* *$ & $* *$ & $* *$ & $* *$ & $* *$ & $* *$ & $* *$ & $* *$ \\
\hline Elevation & $* *$ & $* *$ & $* *$ & $* *$ & $* *$ & $* *$ & NS & $* *$ & $* *$ \\
\hline Species density & $* *$ & $* *$ & $* *$ & $* *$ & $* *$ & $* *$ & $* *$ & $* *$ & $* *$ \\
\hline $\begin{array}{l}\text { Residuals from } \\
\text { Multiple regression }\end{array}$ & $* *$ & $* *$ & $* *$ & $* *$ & $* *$ & $* *$ & $* *$ & $* *$ & NS \\
\hline
\end{tabular}

NS indicates that the value of $I$ is not statistically significant at $P \leq 0.05$. **I is significant at the level of $P \leq 0.01$. PET, potential evapotranspiration; AET, actual evapotranspiration.

Table 4 Results of standard, linear, multiple regression of species density on climatic and physiographical variables. All variables were $\log _{\mathrm{e}}$-transformed before analysis.

(a) Best regression model (passes nested $F$-tests, all coefficients significant at $P=0.05$, low multicollinearity)

Regression model

Species density $=-69.25+2.53($ annual minimum temperature $)+9.88($ annual maximum temperature $)+0.24($ AET $)+0.06($ relief $)+$

0.18 (elevation) + error; $n=386$ (two outliers omitted)

Regression diagnostics

$R^{2}=0.88$

Adjusted $R^{2}=0.88, P=0.000000$

Standard error of regression $=0.181$

\begin{tabular}{lllr}
\hline Independent variable & Coefficient & Standard error of coefficient & $P$-value \\
\hline Annual minimum temperature & 2.532 & 0.200 & 0.0000 \\
Annual maximum temperature & 9.876 & 0.822 & 0.0000 \\
Annual AET & 0.236 & 0.025 & 0.0000 \\
Relief & 0.065 & 0.014 & 0.0000 \\
Elevation & 0.175 & 0.017 & 0.0000
\end{tabular}

(b) Alternate regression model (passes nested F-test, 1 coefficient non-significant at $P=0.05$, high multicollinearity of some variables)

Regression model

Species density $=-73.21+2.63$ (annual minimum temperature $)+10.50$ (annual maximum temperature $)-0.03(\mathrm{PET})+0.24(\mathrm{AET})+$ 0.06 (relief) +0.18 (elevation) + error; $n=386$ (two outliers omitted)

Regression diagnostics

$R^{2}=0.88$

Adjusted $R^{2}=0.88, P=0.000000$

Standard error of regression $=0.181$

\begin{tabular}{lccc}
\hline Independent variable & Coefficient & Standard error of coefficient & $P$-value \\
\hline Annual minimum temperature & 2.633 & 0.315 & 0.0000 \\
Annual maximum temperature & 10.496 & 1.712 & 0.0000 \\
Annual PET & $-0.026(\mathrm{NS})$ & 0.064 & 0.6798 \\
Annual AET & 0.240 & 0.026 & 0.0000 \\
Relief & 0.064 & 0.015 & 0.0000 \\
Elevation & 0.178 & 0.019 & 0.0000 \\
\hline
\end{tabular}

PET, potential evapotranspiration; AET, actual evapotranspiration; NS, not significant. 
(Appendices 1-3 present the results of the full model, nested $F$-tests and auxiliary $R^{2}$ values.) We identified a 'best' model and an alternate model and discuss only these two below.

Table 4 reports two reduced regression models. Each contains a subset of temperature and moisture variables and both topography variables, fulfilling the expectation that all three groups of environmental attributes should contribute to the prediction of species density. The first model (Table 4a) satisfies all the criteria for a satisfactory regression model. The second model (Table 4b) satisfies only some of the criteria, but we included it for the purpose of comparison with previous studies of North American mammals using many of the same environmental variables. The two models have identical values (to the third decimal place) for the standard error of regression and $R^{2}$, and these values differ non-significantly (at $P=0.01$ ) from those in the full model (Appendix 2). The models differ by only one variable: the model in Table $4 \mathrm{~b}$ contains annual PET. This variable has high collinearity with both temperature variables and its coefficient is non-significant. Otherwise, both models are fairly successful at predicting species density. Inspection of residuals (observed - predicted values of species density) revealed two outliers, the southernmost quadrats of Baja California; their values of species density are quite lowa well known peninsular phenomenon (Fig. 2). We omitted these quadrats and redid the regression. Both models improved slightly, and the results in Table 4 reflect the omission of these outliers. The residuals showed no heteroskedasticity in relation to the independent variables or predicted species density.

The ecological meaning of the regression model in Table $4 \mathrm{a}$ is that species density is predicted as a positive function of proportional change in annual minimum temperature (winter temperature), annual maximum temperature (summer temperature), mean annual AET, relief and elevation. Each environmental variable has a positive effect, holding the effects of the other independent variables constant. Table 5 shows predicted values compared with observed values of species density for actual environmental conditions in 11 quadrats representing different regions of North America, based on the best regression model (Table 4a). Predicted values are fairly close to observed values for most regions except for the southernmost example, where the error is quite large ( 129 vs. 178$)$.

The regression models of Table 4 include quadrats from the entire continent. Earlier work indicated that certain environmental variables vary as predictors of species richness in different regions of North America. Kerr \& Packer (1997) found that mean annual PET was the best predictor of species richness in regions where annual PET $<1000 \mathrm{~mm}$, but that topographical relief (elevation variability) was the best predictor in regions where annual PET $\geq 1000 \mathrm{~mm}$. The threshold value $(1000 \mathrm{~mm})$ of annual PET forms an isoline that stretches from east to west just south of the border between Canada and the USA.

To evaluate further the possibility of geographical variation in the relationship between environmental variables and mammalian species density, we recalculated the regression model of Table $4 \mathrm{~b}$ for different regions of North America. We used this model rather than the model in Table 4 a so as to compare PET in our results with PET in earlier studies. Table $6 a$ reports the regression coefficients for the six environmental variables in the regression model for successively greater areas from northern to southern latitudes. Among columns, the only aspect of the model that changes is the number and geographical distribution of the cases. In Table $6 \mathrm{a}$, the environmental variables with significant regression coefficients change strikingly among regions. For quadrats north of $60^{\circ} \mathrm{N}$, only annual maximum temperature and relief have significant coefficients. Annual PET becomes important as the area increases to the south, but does not have a significant coefficient for quadrats from the entire continent. Relief is significant for all regions, but elevation is significant only when the more southern regions are included.

Table 5 Predicted values of species density for a range of actual values of climatic and physiographical variables. Predictions based upon best regression model, Table 4a. Although the variables were log-transformed in the regression model, their untransformed values are given below for ease of interpretation. Each row represents data from a single quadrat, representing different regions of North America.

\begin{tabular}{|c|c|c|c|c|c|c|c|}
\hline Region & $\begin{array}{l}\text { Annual } \\
\text { minimum } \\
\text { temperature }\left({ }^{\circ} \mathrm{C}\right)\end{array}$ & $\begin{array}{l}\text { Annual } \\
\text { maximum } \\
\text { temperature }\left({ }^{\circ} \mathrm{C}\right)\end{array}$ & $\begin{array}{l}\text { Annual } \\
\text { AET } \\
(\mathrm{mm})\end{array}$ & $\begin{array}{l}\text { Relief } \\
(\mathrm{m})\end{array}$ & $\begin{array}{l}\text { Elevation } \\
(\mathrm{m})\end{array}$ & $\begin{array}{l}\text { Predicted } \\
\text { species density } \\
\text { (spp./quadrat) }\end{array}$ & $\begin{array}{l}\text { Observed } \\
\text { species density } \\
\text { (spp./quadrat) }\end{array}$ \\
\hline North-central Canada & -47.0 & 24.5 & 215 & 152 & 175 & 25 & 20 \\
\hline Northern Quebec & -44.0 & 24.0 & 245 & 305 & 200 & 28 & 30 \\
\hline $\begin{array}{l}\text { Southern British Columbia } \\
\& \text { Alberta }\end{array}$ & -38.0 & 34.5 & 295 & 3103 & 2000 & 78 & 68 \\
\hline North Dakota plains & -37.5 & 35.5 & 500 & 183 & 475 & 59 & 69 \\
\hline $\begin{array}{l}\text { Eastern New York \& SW } \\
\text { Vermont }\end{array}$ & -27.5 & 34.5 & 750 & 1204 & 500 & 80 & 68 \\
\hline Great Basin, Nevada & -22.0 & 37.0 & 270 & 2530 & 2200 & 98 & 85 \\
\hline Mid-California & -2.5 & 41.0 & 300 & 3530 & 600 & 112 & 107 \\
\hline S. Mississippi Valley, Arkansas & -12.0 & 36.5 & 960 & 152 & 150 & 74 & 58 \\
\hline $\begin{array}{l}\text { S. New Mexico \& N. central } \\
\text { Mexico }\end{array}$ & -12.0 & 36.5 & 280 & 1679 & 1500 & 100 & 109 \\
\hline Central Mexican highlands & 1.0 & 33.0 & 650 & 2440 & 2000 & 130 & 131 \\
\hline S. Nicaragua \& N. Costa Rica & 15.0 & 30.0 & 975 & 2590 & 600 & 129 & 178 \\
\hline
\end{tabular}


Table 6 Coefficients of climatic and physiographical variables from standard multiple regression of species density on environmental variables for different regions of North America, using the regression model in Table $4 \mathrm{~b}$. All variables were $\log _{\mathrm{e}}$-transformed before analysis. (a) Results for successively greater geographical regions, defined by lower latitudinal limits. Coefficients for the model with all quadrats are the same as in Table 4b. (b) Results for discrete latitudinal or longitudinal blocks of North America. Both sets of results show that environmental variables vary with geographical region as significant predictors of species density. X refers to midpoint latitude of quadrat, Y to midpoint longitude of quadrat.

(a)

\begin{tabular}{|c|c|c|c|c|c|c|}
\hline & $>60^{\circ} \mathrm{N}$ & $>50^{\circ} \mathrm{N}$ & $>40^{\circ} \mathrm{N}$ & $>30^{\circ} \mathrm{N}$ & $>20^{\circ} \mathrm{N}$ & All quadrats \\
\hline$n$ & 71 & 156 & 248 & 324 & 358 & 386 \\
\hline Annual min. temperature & NS & NS & NS & -0.77 & NS & 2.63 \\
\hline Annual max. temperature & 16.33 & 10.99 & 11.66 & 8.75 & 7.70 & 10.50 \\
\hline Annual PET & NS & 0.48 & 0.38 & 0.37 & 0.30 & NS \\
\hline Annual AET & NS & NS & NS & NS & 0.10 & 0.24 \\
\hline Relief & 0.11 & 0.07 & 0.06 & 0.01 & 0.06 & 0.06 \\
\hline Elevation & NS & NS & NS & 0.10 & 0.13 & 0.18 \\
\hline $\mathrm{S}_{\mathrm{e}}$ & 0.16 & 0.13 & 0.12 & 0.13 & 0.15 & 0.18 \\
\hline$R^{2}$ & 0.84 & 0.88 & 0.92 & 0.92 & 0.90 & 0.88 \\
\hline
\end{tabular}

(b)

\begin{tabular}{lccccc}
\hline & $\begin{array}{l}\mathrm{X}>50^{\circ} \mathrm{N} \\
(\text { boreal })\end{array}$ & $\begin{array}{l}0^{\circ}<\mathrm{X} \leq 50^{\circ} \mathrm{N} \\
\text { (temperate) }\end{array}$ & $\begin{array}{l}\mathrm{X} \leq 30^{\circ} \mathrm{N} \\
\text { (tropical) }\end{array}$ & $\begin{array}{l}\mathrm{Y} \leq 100^{\circ} \mathrm{W} \\
\text { (eastern) }\end{array}$ & $\begin{array}{l}\mathrm{Y}>100^{\circ} \mathrm{W} \\
(\text { western) }\end{array}$ \\
\hline$n$ & 156 & 168 & 62 & 192 & 194 \\
Annual min. temperature & $\mathrm{NS}$ & 0.95 & 2.20 & 4.35 & 0.73 \\
Annual max. temperature & 10.99 & 3.60 & $\mathrm{NS}$ & 19.08 & 3.98 \\
Annual PET & 0.48 & 0.13 & $\mathrm{NS}$ & -0.38 & 0.31 \\
Annual AET & $\mathrm{NS}$ & $\mathrm{NS}$ & 0.34 & 0.26 & 0.20 \\
Relief & 0.07 & $\mathrm{NS}$ & 0.15 & 0.08 & 0.04 \\
Elevation & $\mathrm{NS}$ & 0.17 & 0.11 & 0.17 & 0.14 \\
$\mathrm{~S}_{\mathrm{e}}$ & 0.13 & 0.09 & 0.13 & 0.20 & 0.13 \\
$R^{2}$ & 0.88 & 0.86 & 0.89 & 0.88 & 0.92 \\
\hline
\end{tabular}

PET, potential evapotranspiration; AET, actual evapotranspiration; $\mathrm{S}_{\mathrm{e}}$, standard error of regression; $n=$ number of quadrats in each analysis; NS, not significant.

Also, we divided the continent into three discrete latitudinal blocks and two longitudinal ones (Table 6b). Each latitudinal block has a different set of variables with significant coefficients, with no single variable having a significant effect in all three regions. For the two longitudinal blocks, all six environmental variables were significant, although the magnitudes vary, and annual PET has the opposite effect on species richness in the eastern and western regions.

Other regression statistics also vary among regions. In Table $6 \mathrm{a}$, the standard error of regression $\left(\mathrm{S}_{\mathrm{e}}\right)$ is lowest $(0.12$ in units of $\ln$ species richness) for the set of quadrats greater than $40^{\circ} \mathrm{N}$, although the values of $S_{e}$ are similar for quadrats $>50^{\circ} \mathrm{N}$ and $>30^{\circ} \mathrm{N}$. In Table $6 \mathrm{~b}, \mathrm{~S}_{\mathrm{e}}$ is lowest $(0.09)$ for the temperate quadrats and higher $(0.13)$ for both boreal and tropical quadrats. Between the two longitudinal blocks, $S_{e}$ is substantially lower for the western quadrats. The $R^{2}$ values are fairly high for all geographical subsets shown in Table 6 , with the highest value $(0.92)$ in Table 6 a for quadrats $>40^{\circ} \mathrm{N}$ and $>50^{\circ} \mathrm{N}$, and in $6 \mathrm{~B}$ for the western quadrats. These results are not presented as definitive models for these different regions. This would require more comprehensive evaluation, like the procedure described above for the model based on the entire continent. The point here is that the continental model shows considerable variation in the significance of its parameters and in the standard error of regression for different regions of the continent.

The regression analyses in Tables 4 and 6 demonstrate that half a dozen or fewer environmental variables predict a high proportion of the variation in species density of North American mammals. Different environmental variables make a significant contribution to the prediction in different geographical regions of the continent. There are several relationships among the environmental variables and species density over North America, not one homogeneous relationship.

These results agree in several respects with those of Currie (for mammals, 1991) and of the elaboration of his work by Kerr \& Packer (1997). In both studies, quadrats south of $c .30^{\circ} \mathrm{N}$ were not included. Currie used non-linear regression methods and included a greater number of environmental variables. His study and this one both found that for quadrats $>30^{\circ} \mathrm{N}$, environmental variables explain over $90 \%$ of the variation in mammalian species richness. Variables related to energy-PET 
and the temperature variables-are important to the best regression models, as are variables representing topographical complexity and elevation. The work of Kerr \& Packer and this study demonstrated that the significance of PET and relief as predictors of species richness varies with continental region.

As a final part of the regression analysis, we examined the relationship between species density and latitude and the residual variation in species density in relation to latitude. Figure 6a illustrates species density vs. latitude for all 388 quadrats. A logarithmic curve fits the trend reasonably well (better than a line). The residuals for the best regression model (Table 4a) cluster around 0 (Fig. 6b), and the correlation coefficient is low and marginally significant at $P=0.05(P=0.02)$. A cluster of positive residuals at low latitudes represents tropical quadrats for which the regression model usually underestimates species richness (e.g. the last entry in Table 5). The pattern of residuals indicates that almost no latitudinal gradient in species density remains after the effects of the five environmental variables in the model have been accounted for. Spatial autocorrelation analysis of the residuals shows positive autocorrelation of residuals over distances up to $c .1000 \mathrm{~km}$ and low positive or low negative autocorrelation over greater distances (Fig. 6c). The statistical significance of $I$ for the residuals is given in Table 3. The pattern in Fig. 6(c) suggests that over relatively short distances, there remains a small, measurable, spatially autocorrelated component to species density. But this component does not persist over greater distances; rather, the pattern suggests an underlying process that is random with respect to distance (Sokal \& Oden, 1978), in contrast with the correlogram for species density (Fig. 5d).

The multiple regression analysis indicates that the environmental variables account for a high percentage of the variance in species density. Five environmental variables-annual minimum temperature, annual maximum temperature, actual evapotranspiration, relief and elevation-produce the most satisfactory model to predict species density for the entire continent. The residuals of this regression do not show strong spatial structure, unlike all the original variables. This contrast indicates that most of the spatial structure in species density is explained by the spatial structure in the environmental variables.

\section{(5) Ordination of climatic variables}

The goal of principal component analysis was to summarize the climatic variables by a smaller number of new variables that express most of the variation in the original data. Figure 7 and Table 7 show the results. The first two axes each have Eigen values of $\geq 1$ and together express $87 \%$ of the variance in the original data; the other axes have Eigen values $<1$ and are not discussed (Hamilton, 1992). The first axis contains $71 \%$ of the variance; the loadings indicate that this axis is dominated by three temperature variables-annual range of temperature, monthly minimum temperature and frostfree period. In Fig. 7(a), these variables are virtually collinear, indicating a high correlation among them. The gradient expressed here contrasts localities with a high annual range of temperature and a short growing season vs. localities with high
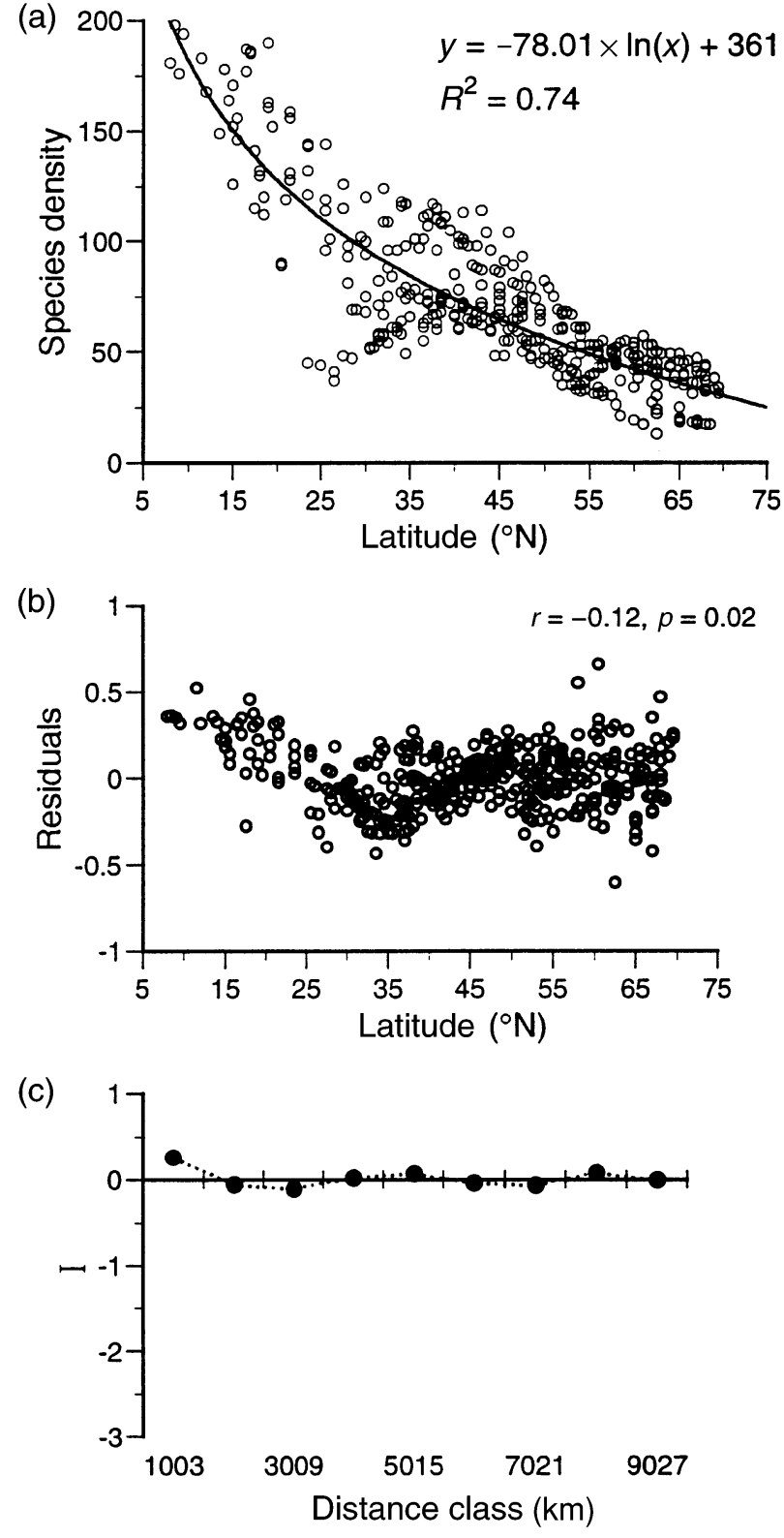

Figure 6 Spatial gradients in species density before and after regression of species density on environmental variables. (a) Species density vs. latitude for all quadrats $(n=388)$. The fitted curve is logarithmic. (b) Residuals of species density vs. latitude, from the regression model of Table 4a. There is low but significant correlation (at $P=0.05$ ), indicating that the environmental variables account for most of the latitudinal variation in species density. (c) Spatial autocorrelation of the residuals indicates that only a small amount of spatial structure remains in the residuals of species density, as compared with Fig. 5(d), after regression on the environmental variables (model of Table 4a).

monthly minimum temperature (warm winter) and a long growing season. The other climatic variables are moderately to strongly correlated with the first axis. The second axis, representing $16 \%$ of the variance, expresses a moisture gradient; precipitation and annual AET have high negative loadings, 
(a)

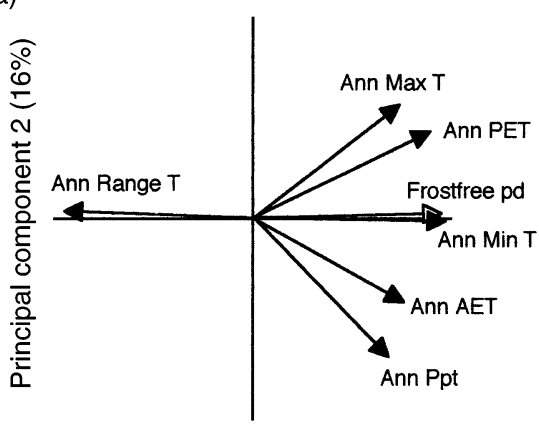

Principal component 1 (71\%)

(c)

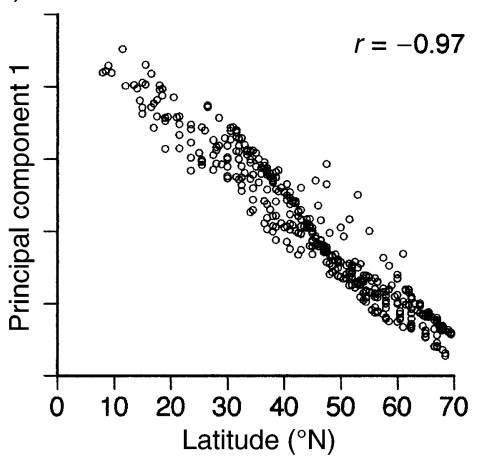

(b)

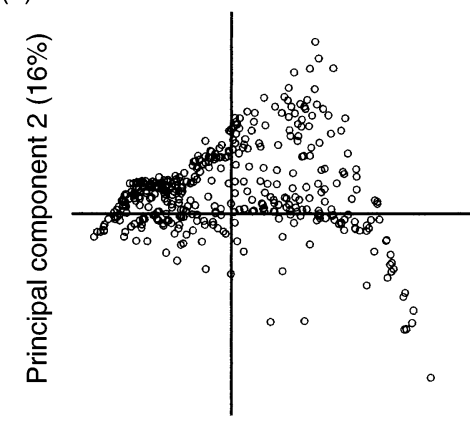

Principal component 1 (71\%)

(d)

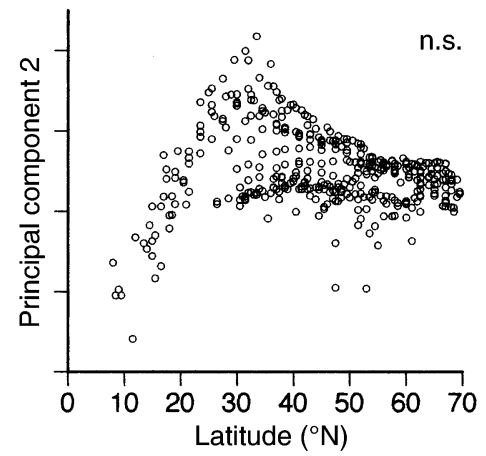

Figure 7 Results of principal component analysis of seven climatic variables, based on data for all quadrats $(n=388)$. (a) Loadings of climatic variables on principal components 1 and 2 , together containing $87 \%$ of the variance in the original data. The first axis represents seasonality of temperature; the second axis represents a gradient in moisture. (b) Scores of the quadrats in the ordination space of (a). Quadrats of northern regions plot along the negative end of the first axis, representing boreal and arctic biomes. Southern quadrats in areas of moderate to high precipitation lie in the lower right quadrant. Southern quadrats in mesic to xeric areas lie in the upper right quadrant. (c) Principal component 1 in relation to latitude, indicating a high correlation between the first axis and latitude. (d) Principal component 2 vs. latitude, indicating greater variation in moisture and aridity at low latitudes than at high latitudes. Abbreviations: Ann Range T = annual range of temperature, Ann Max T = annual maximum temperature, Ann PET = annual potential evapotranspiration, Ann Min T = annual minimum temperature, Ann AET = annual actual evapotranspiration, Ann Ppt = annual precipitation, NS $=$ not significant.
Table 7 Results of principal component analysis of seven climatic variables. The analysis was performed on the correlation matrix, since variables are in different scales of measurement; see also Fig. 7. Loading of variables on first four axes.

\begin{tabular}{lrrrr}
\hline Climatic variable & Axis 1 & Axis 2 & Axis 3 & Axis 4 \\
\hline Annual range of temperature & -0.93 & 0.04 & -0.30 & 0.06 \\
Annual minimum temperature & 0.96 & 0.01 & 0.25 & 0.02 \\
Annual maximum temperature & 0.71 & 0.55 & -0.38 & -0.20 \\
Length of frostfree period & 0.94 & 0.02 & 0.15 & 0.19 \\
Annual precipitation & 0.68 & -0.68 & -0.04 & -0.27 \\
Annual PET & 0.88 & 0.43 & -0.01 & 0.02 \\
Annual AET & 0.74 & -0.41 & -0.48 & 0.21 \\
\% variance explained & 71 & 16 & 8 & 3 \\
Eigen value & 4.97 & 1.11 & 0.55 & 0.20 \\
\hline
\end{tabular}

and annual maximum temperature and annual PET have moderately high positive loadings (Fig. 7a). The first principal component captures much of the information representing temperature and energy. The second axis represents abundant moisture at the negative end and high moisture demand at the positive end.

Figure 7 (b) shows the scores of quadrats in relation to the first two principal components. The northernmost quadrats fall along the negative end of the first axis, representing boreal and arctic regions. Southern quadrats in areas of moderate to high precipitation lie in the lower right quadrant. Southern quadrats in mesic to xeric areas lie in the upper right quadrant.
Quadrat scores on the first principal component are highly correlated with latitude (Fig. $7 \mathrm{c}$ ); the pattern is quite similar to that of annual minimum temperature and frostfree period with latitude (Fig. 3b,d) and is consistent with the climatic interpretation of the first axis. Quadrat scores on the second principal component show no significant linear correlation with latitude (Fig. 7d). The general pattern is unimodal with low variation in moisture at high latitudes and increasing variation at lower latitudes, especially south of $c .35^{\circ} \mathrm{N}$.

\section{(6) Faunal variables in relation to climatic gradients}

The frequency of species in each ecological category is plotted in relation to the first two principal-component axes based on climatic variables, in Figs 8 and 9. Figure 8 depicts the trophic and size categories in relation to the first principal component. Recall that this axis expresses a gradient in the seasonality of temperature, with high seasonality at the negative end and low seasonality and a long growing season at the positive end (Fig. 7a). Several patterns are evident in Fig. 8. For several categories, there is a monotonic increase, sometimes above a threshold value, in the frequency of species with decreasing seasonality of temperature (e.g. Fig. 8a, aerial insectivores; Fig. 8e, omnivores; Fig. 8f, frugivores; Fig. 8k, size class 3). A second pattern is unimodal, with the frequency of species highest in the middle and declining toward both ends of the temperature-seasonality gradient. Carnivores (Fig. 8d), herbivores (Fig. 8h), size class 5 (Fig. 8m) and size class 6 (Fig. 8n) show this pattern. The remaining ecological variables show 
(a) Aerial insectivores

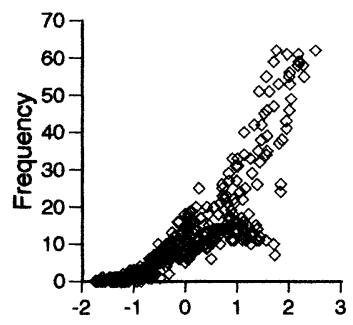

(c) Aquatic faunivores

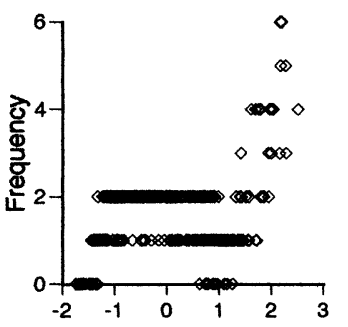

(e) Omnivores

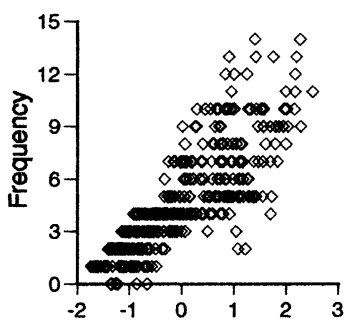

(g) Granivores

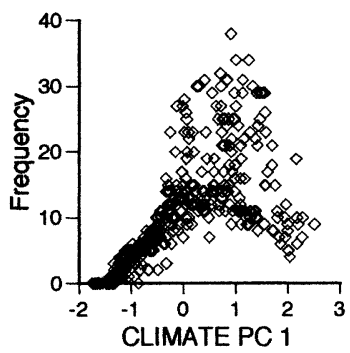

(b) Terrestrial invertivores

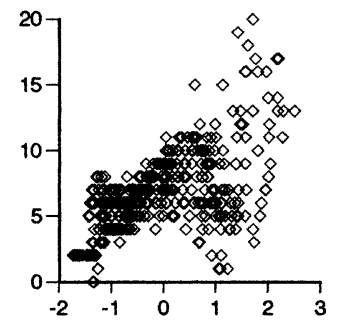

(d) Carnivores

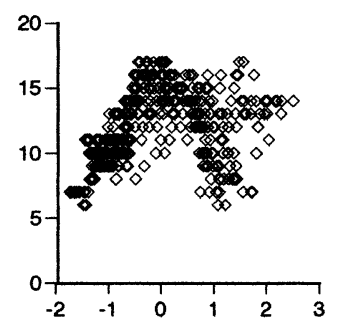

(f) Frugivores

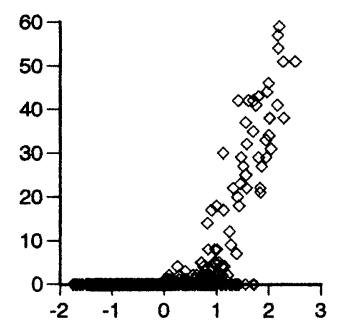

(h) Herbivores

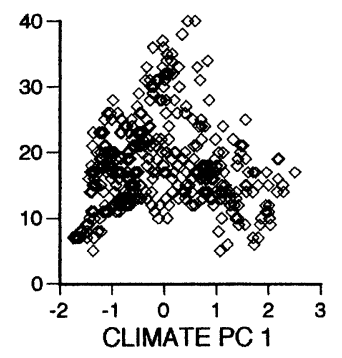

(i) Size class $1(<10 \mathrm{~g})$

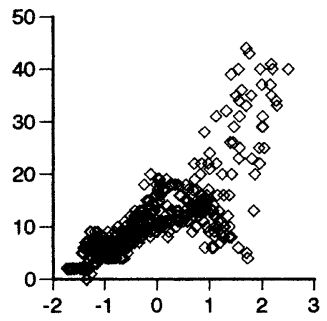

(k) Size class $3(101-1000 \mathrm{~g})$

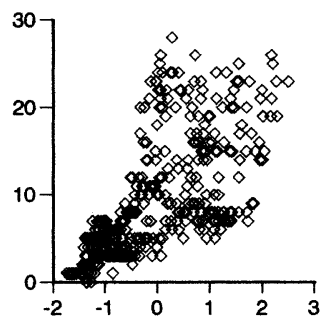

(m) Size class $5(11-100 \mathrm{~kg})$

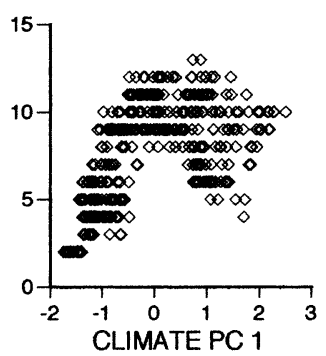

(j) Size class $2(11-100 \mathrm{~g})$

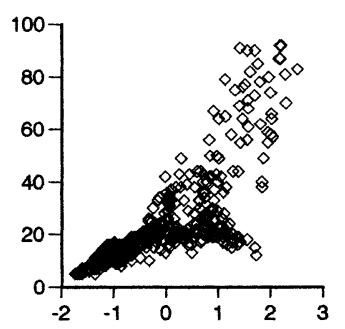

(I) Size class $4(1-10 \mathrm{~kg})$

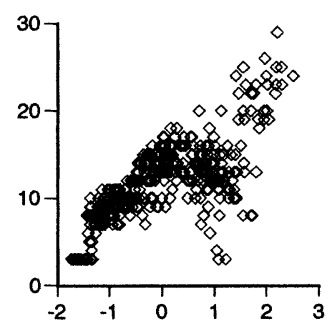

(n) Size class $6(101-1000 \mathrm{~kg})$

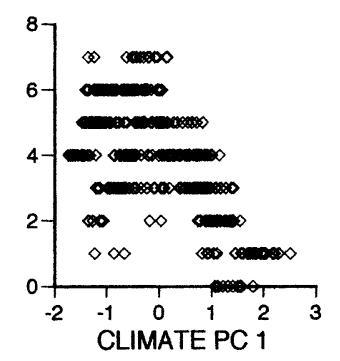

Figure 8 Ecological structure of mammalian faunas in relation to principal component 1, a gradient in seasonality of temperature, from Fig. 7. The frequency of species in each trophic and size category is shown in relation to principal component 1 . Note that the scale of the vertical axis varies among ecological categories. Data for all quadrats $(n=388)$ are shown. (a) Aerial insectivores, (b) terrestrial invertivores, (c) aquatic faunivores, (d) carnivores, (e) omnivores, (f) frugivores, (g) granivores, (h) herbivores, (I) size class $1(<10 \mathrm{~g})$, (j) size class $2(11-100 \mathrm{~g})$, (k) size class $3(101-1000 \mathrm{~g})$, (1) size class $4(1-10 \mathrm{~kg}),(\mathrm{m})$ size class $5(11-100 \mathrm{~kg}),(\mathrm{n})$ size class $6(101-1000 \mathrm{~kg})$. Several patterns are evident; see text for explanation.

a combination of monotonic and unimodal relationships. Terrestrial invertivores (Fig. 8b), granivores (Fig. 8g) and size classes 1, 2 and 4 (Fig. 8i,j,1, respectively) exhibit the hybrid pattern. For these categories, the number of species increases with decreasing seasonality of temperature over high to moderate values of seasonality (left side of axis). Over moderate to low values of seasonality, there are two opposing trajectories: one in which the number of species declines with decreasing seasonality and one in which the number of species increases with decreasing seasonality. The similarity between some of the relationships for trophic variables and size variables arises because the same species contribute to both sets of patterns (e.g. aerial insectivores and size classes 1 and 2). But no size class maps precisely onto a single trophic category, nor vice versa.

Figure 9 depicts the ecological variables in relation to the second principal component, representing a gradient from high annual moisture at the negative end to high annual moisture demand at the positive end. Trends are less clear in relation to 
(a) Aerial insectivores

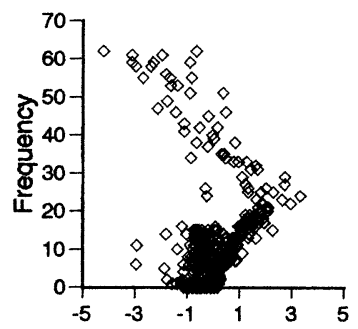

(c) Aquatic faunivores

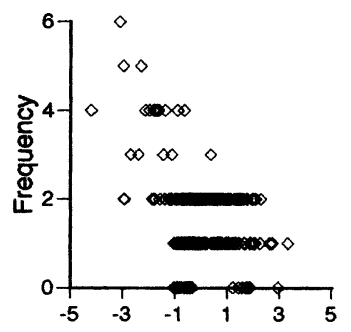

(e) Omnivores

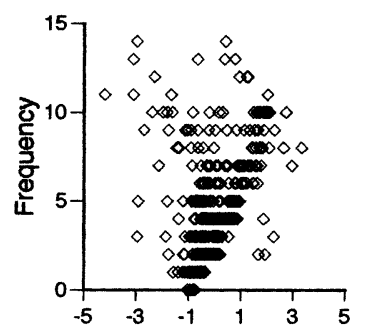

(g) Granivores

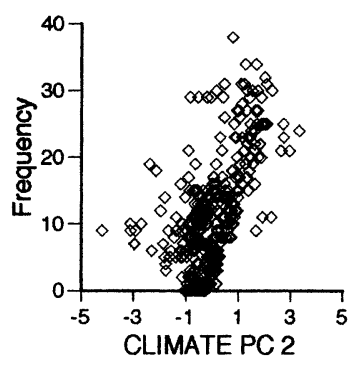

(b) Terrestrial invertivores

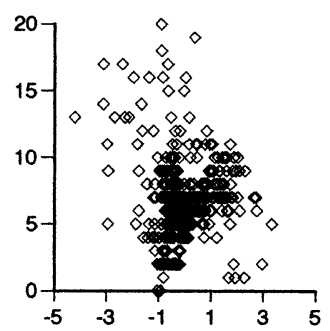

(d) Carnivores

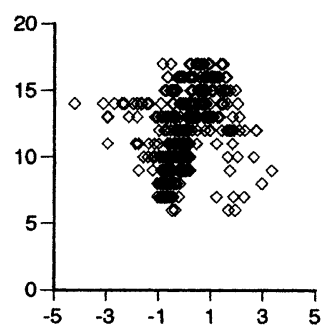

(f) Frugivores

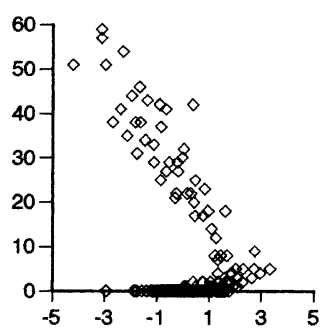

(h) Herbivores

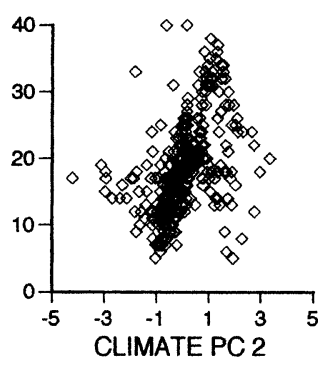

(i) Size class $1(<10 \mathrm{~g})$

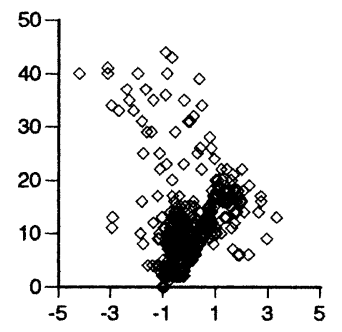

(k) Size class $3(101-1000 \mathrm{~g})$

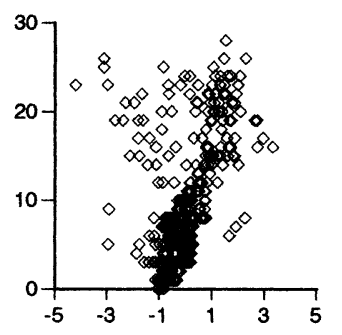

(m) Size class $5(11-100 \mathrm{~kg})$

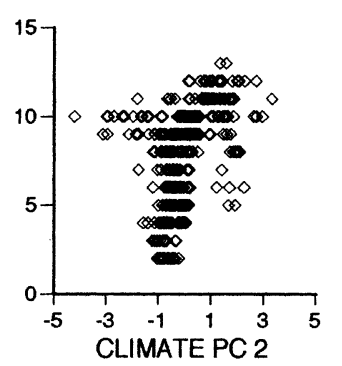

(j) Size class $2(11-100 \mathrm{~g})$

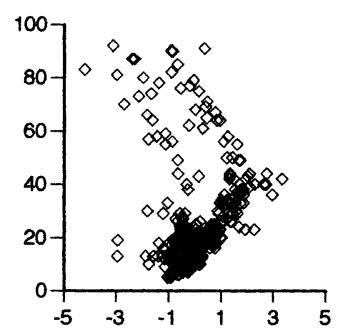

(I) Size class $4(1-10 \mathrm{~kg})$

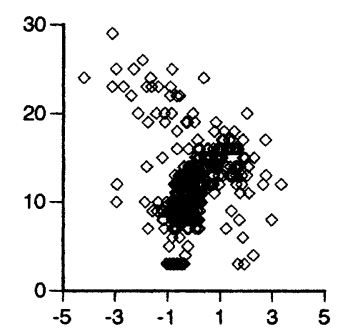

(n) Size class $6(101-1000 \mathrm{~kg})$

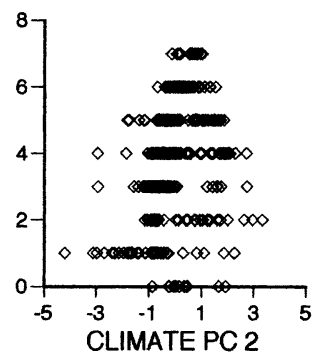

Figure 9 Ecological structure of mammalian faunas in relation to a moisture gradient, as represented by principal component 2, from Fig. 7. The frequency of species in each trophic and size category is shown in relation to principal component 2 . Note that the scale of the vertical axis varies among ecological categories. Data for all quadrats $(n=388)$ are shown. (a) Aerial insectivores, (b) terrestrial invertivores, (c) aquatic faunivores, (d) carnivores, (e) omnivores, (f) frugivores, (g) granivores, (h) herbivores, (I) size class 1 (< $10 \mathrm{~g})$, (j) size class $2(11-100 \mathrm{~g})$, (k) size class 3 (101$1000 \mathrm{~g}),(1)$ size class $4(1-10 \mathrm{~kg}),(\mathrm{m})$ size class 5 (11-100 kg), (n) size class 6 (101-1000 kg). Several noisy trends are evident; see text for explanation.

the moisture gradient than to the temperature gradient. A linear but noisy positive relationship with annual moisture (negative slope) characterizes aquatic faunivores (Fig. 9c), frugivores when present (Fig. 9f), and some aerial insectivores (Fig. 9a). Some categories show two divergent patterns: with an increase in species from low to moderate numbers with decreasing moisture and increasing summer temperature and annual PET (desert conditions) and an increase in species from mod- erate to high values with increasing moisture. This pattern describes aerial insectivores (Fig. 9a), omnivores (Fig. 9e) and size classes 1 (Fig. 9i) and 2 (Fig. 9j). More species of granivores (Fig. 9g) and of size classes 3 (Fig. 9k) and 4 (Fig. 9l) occur where moisture demand is higher. Carnivores (Fig. 9d), herbivores (Fig. 9h), and size classes 5 (Fig. 9m) and 6 (Fig. 9n) exhibit somewhat unimodal patterns; the mode lies on the drier side of the moisture gradient. 
Together, Figs 8 and 9 indicate that different ecological subsets of mammalian faunas change in different ways along the same climatic temperature and moisture gradients at the continental scale. The trends are clearer in relation to the temperature gradient than to the moisture gradient. Some of the patterns in Fig. 9 suggest that the moisture gradient interacts with other environmental variables not included in the principal component analysis. The physiographical variables were not part of the principal component analysis but were included in the canonical analyses described next.

\section{(7) Redundancy analyses of faunal and environmental data}

Redundancy analysis expresses the relationship between faunal and environmental variables simultaneously. Tables 8 , 9, 10 and 11, and Figs 10,11 and 12 present summary statistics and ordination diagrams for two redundancy analyses, one with all faunal and environmental variables and a more satisfactory one with a reduced set of environmental variables.

The analysis with all faunal and environmental variables (Table 10a) has heuristic value, but is unsatisfactory because

Table 8 Evaluation of environmental variables through regression of faunal variables on environmental variables. (a) Coefficient of determination $\left(R^{2}\right)$ for regression of faunal variables on each environmental variable individually. (b) Results of forward selection of environmental variables through forward stepwise regression.

Variable $R^{2}$

(a)

Annual minimum temperature $\quad 0.57$

Annual range of temperature $\quad 0.56$

Frostfree period $\quad 0.43$

Annual PET $\quad 0.39$

Annual maximum temperature $\quad 0.23$

Annual precipitation $\quad 0.20$

$\begin{array}{ll}\text { Relief } & 0.19\end{array}$

$\begin{array}{ll}\text { Annual AET } & 0.16\end{array}$

Elevation $\quad 0.13$

All environmental variables $\quad 0.77$

(b) *

Annual minimum temperature $\quad 0.57$

$\begin{array}{lr}+ \text { Elevation } & 0.67\end{array}$

+ Annual PET $\quad 0.71$

$\begin{array}{ll}+ \text { Annual AET } & 0.75\end{array}$

$\begin{array}{ll}+ \text { Frostfree period } & 0.76\end{array}$

+ Annual precipitation $\quad 0.76$

$\begin{array}{ll}+ \text { Annual maximum temperature } & 0.77\end{array}$

$\begin{array}{ll}+ \text { Relief } & 0.77\end{array}$

+ Annual range of temperature NS

${ }^{*} R^{2}$ is the cumulative value of the coefficient of determination as additional variables are added to the analysis as explanatory variables. The $F$-ratio of each analysis shown is significant at $P \leq 0.01$. The last variable listed, annual range of temperature, made a non-significant $(P>0.05)$ contribution when added.

PET, potential evapotranspiration; AET, actual evapotranspiration. of high multicollinearity among some environmental variables. In order to determine a better model with fewer environmental variables, it is necessary to examine these variables individually and cumulatively for their ability to predict the faunal data. In Table $8 \mathrm{a}, R^{2}$ indicates the fraction of the variance in the faunal data explained by each environmental variable individually. Annual minimum temperature has the highest $R^{2}(0.57)$ and elevation the lowest $(0.13)$. All the environmental variables together explain $77 \%$ of the variance in the faunal data. Forward selection of environmental variables (Table $8 \mathrm{~b}$ ) indicates how the variables add cumulatively to the explained variation of faunal data. Beyond frostfree period, additional variables add less than $1 \%$ to $R^{2}$. We selected the first five variables from Table $8 \mathrm{~b}$ for the reduced model; these include representatives from the temperature, moisture and topography variables, as in the regression models. The five environmental variables differ from those of the regression model because here they are constrained by the ecological categories.

Table 9 gives summary statistics for the two redundancy analyses. It includes Eigen values for the canonical axes, which represent linear combinations of the environmental variables; the fraction of variance in the constrained ordination explained by each axis; the faunal-environmental (canonical) correlations between pairs of canonical axes; the redundancy index of faunal data given the environmental data (proportion of total variance in the faunal data explained by the environmental variables, in this scaling equivalent to the Eigen value $\times 100)$; the sum of all unconstrained Eigen values ( $=1$ in this scaling); and the sum of canonical (constrained) Eigen values. The redundancy analysis using all nine environmental variables (Table 9 a) accounts for $77 \%$ of the variance in the faunal data (sum of canonical Eigen values $\times 100$ ). Most of the variance in the faunal data is explained by the first two axes, which have high faunal-environmental correlations. The analysis using

Table 9 Summary statistics for redundancy analyses of faunal and environmental data. See text for explanation. (a) Redundancy analysis with all faunal variables, all environmental variables (see Fig. 10a). (b) Redundarey analysis with all faunal variables and four climatic variables and elevation (see Fig. 10c).

\begin{tabular}{lcclll}
\hline Axes & 1 & 2 & 3 & 4 \\
\hline (a) & & & & \\
Eigen values & 0.67 & 0.08 & 0.02 & 0.01 \\
Fraction of variance explained & 86.4 & 10.7 & 1.9 & 0.7 \\
Faunal-environmental correlations & 0.90 & 0.88 & 0.67 & 0.74 \\
Redundancy, faunallenvironmental (\%) & 66.6 & 8.2 & 1.5 & 0.6 \\
Sum of all unconstrained Eigen values & 1.00 & & & \\
Sum of all canonical Eigen values & 0.77 & & & \\
(b) & & & & \\
Eigen values & 0.66 & 0.08 & 0.01 & 0.01 \\
Fraction of variance explained & 86.8 & 10.8 & 1.6 & 0.7 \\
Faunal-environmental correlations & 0.89 & 0.88 & 0.60 & 0.73 \\
Redundancy, faunallenvironmental (\%) & 65.6 & 8.2 & 1.2 & 0.6 \\
Sum of all unconstrained Eigen values & 1.00 & & & \\
Sum of all canonical Eigen values & 0.76 & & & \\
\hline
\end{tabular}

Faunal-environmental $=$ faunal data, given environmental data. 
(a)

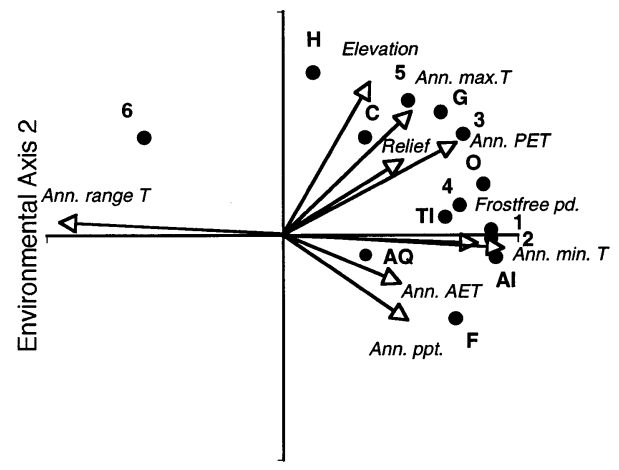

Environmental Axis 1

(c)

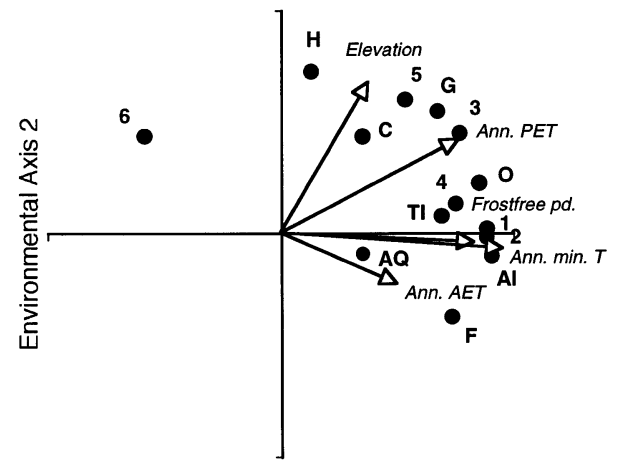

Environmental Axis 1

(b)

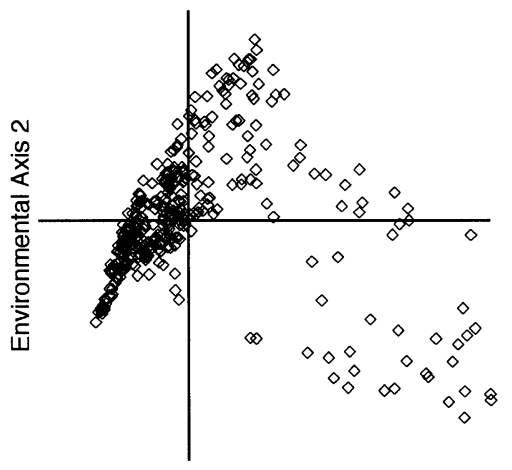

Environmental Axis 1

(d)

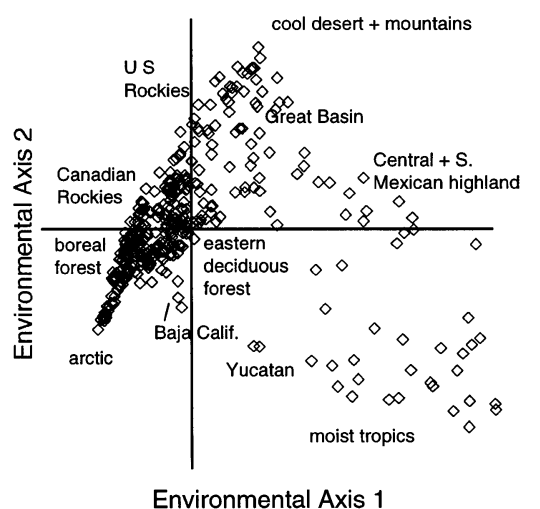

Figure 10 Ordination diagrams or 'biplots' from two redundancy analyses. In (a) and (c), the correlations between environmental variables and faunal variables with environmental Axes 1 and 2 are shown. Environmental variables are represented by arrows, faunal variables by solid circles. Each size category is represented by its number; each trophic category is represented by letter abbreviations shown in Table 1. (a) Analysis with all nine environmental variables and all 14 faunal variables. Note that some of the environmental variables are virtually collinear, indicating high correlation among these variables. In this analysis, the environmental variables account for $77 \%$ of the variance in the faunal data (Table 9a). (b) Scores for the quadrats in the ordination space of (a).

(c) Analysis with four climatic variables and elevation in relation to all 14 faunal variables. In this analysis, the environmental variables explain $76 \%$ of the variance in the faunal data (Table 9b). (d) Scores for quadrats in the ordination space of (c). The bioclimatic or geographical regions for many of the sites are indicated. five environmental variables (Table 9b) is almost as strong in all respects as the one with all environmental variables, but avoids the problems of multicollinearity present in the first analysis. This multicollinearity is illustrated in Fig. 10(a) by the near overlap of three pairs of arrows depicting environmental variables. Also, some of the canonical coefficients for the full model are non-significant (Table 10a). Canonical coefficients are analogous to regression coefficients that result from multiple regression of the faunal data on the environmental variables. The canonical coefficients represent the unique contribution of each environmental variable to each environmental canonical axis, with the other variables held constant. A $t$-test, while not strictly valid in this context, indicates which canonical coefficients differ significantly from 0 (at $P=0.05$, ter Braak \& Smilauer, 1998). Whereas several of the environmental variables have non-significant coefficients in the full model (Table 10a), none of the environmental variables have non-significant coefficients in the reduced model (Table 10b). The intraset correlation coefficients are the product-moment correlations between each environmental variable and the environmental axes (analogous to loadings in canonical correlation analysis, ter Braak \& Smilauer, 1998). The location of the endpoints of the environmental arrows (Fig. 10a,c) is the value of the intraset correlation coefficient on each axis. For the reduced model, the two temperature variables and annual PET have the highest correlations with the first axis, and elevation and PET have the highest correlations with the second axis.

The ordination diagrams (Fig. 10a-d) depict environmental variables, faunal variables and sites in the same ordination space. These 'correlation biplots' conveniently summarize the results of constrained ordination by showing the relative importance of the environmental variables by the length of each arrow; the correlations among the environmental variables by the angle between pairs of arrows (small angle implying high correlation and vice versa); the faunal variables that exhibit the greatest variation in relation to the environmental gradients by the distance of the faunal symbol from the origin; the relationship of faunal variables to individual environmental variables by the orthogonal projection of the faunal symbol onto the arrow of each environmental variable; and the distribution of sites in the same ordination space (Jongman, ter Braak \& Tongeren, 1995). In Fig. 10(a,c), the distribution of environmental and faunal variables is quite similar; the omission of four environmental variables from the reduced model (Fig. 10c) does not alter the basic relationships among environmental and faunal variables relative to the full model 
Table 10 Canonical coefficients and intraset correlation coefficients for redundancy analyses using different sets of environmental variables; results below correspond to analyses in Table 9(a,b). (a) All faunal variables in relation to all environmental variables ( $n=388$ quadrats). (b) All faunal variables in relation to five environmental variables ( $n=388$ quadrats).

\begin{tabular}{lccrr}
\hline & \multicolumn{2}{l}{ Canonical coefficient } & \multicolumn{2}{c}{ Correlation coefficient } \\
\cline { 2 - 5 } Axes & 1 & 2 & 1 & 2 \\
\hline (a) & & & & \\
Annual range of temperature & 0.06 (NS) & $0.03(\mathrm{NS})$ & -0.92 & 0.06 \\
Annual minimum temperature & 1.14 & -0.80 & 0.92 & -0.06 \\
Annual maximum temperature & 0.12 (NS) & -0.01 (NS) & 0.55 & 0.55 \\
Frostfree period & 0.23 & -0.59 & 0.81 & -0.03 \\
Annual precipitation & -0.25 & $0.10(\mathrm{NS})$ & 0.52 & -0.37 \\
Annual PET & -0.75 & 1.81 & 0.75 & 0.43 \\
Annual AET & 0.48 & -0.48 & 0.48 & -0.21 \\
Relief & 0.09 (NS) & 0.03 (NS) & 0.51 & 0.34 \\
Elevation & 0.45 & 0.14 & 0.36 & 0.67 \\
(b) & & & & \\
Annual minimum temperature & 0.93 & -0.75 & 0.93 & -0.06 \\
Frostfree period & 0.27 & -0.60 & 0.81 & -0.04 \\
Annual PET & -0.48 & 1.74 & 0.75 & 0.42 \\
Annual AET & 0.22 & -0.39 & 0.48 & -0.21 \\
Elevation & 0.48 & 0.17 & 0.36 & 0.66 \\
\hline
\end{tabular}

NS, not significant by $t$-test at $P=0.05$. PET, potential evapotranspiration; AET, actual evapotranspiration.
(Fig. 10a). The first environmental axis expresses seasonality of temperature and the second axis contrasts elevation and high summer temperature with high moisture. Ecological categories with numerous species where warm winters prevail (at the right end of first axis) include size categories 1,2 and 4, aerial insectivores, omnivores and terrestrial invertivores. Frugivore species are most numerous under warm and moist conditions (lower right quadrant); so are aquatic faunivores, although there are never more than six species in the same quadrat. Granivores and species in size class 3 are numerous where annual PET is high. Carnivores, herbivores and species in size class 5 are relatively numerous in areas of high elevation. Species in size class 6 are most numerous where seasonality of temperature is high and moisture is relatively low (upper left quadrant).

The distance of each faunal variable from the origin is proportional to the redundancy index for each faunal variable (Table 11). This index indicates the fraction of the variance in the faunal variable explained by the environmental variables; values range from 0 to 1 . (Values on Axis 2 are cumulative.) Variables distant from the origin are well predicted by the analysis and vice versa. Faunal variables with high redundancy indices $(\geq 0.75)$ on the first two axes include size classes 1,2 and 3 , aerial insectivores, omnivores and granivores. Faunal variables with low redundancy indices $(<0.40)$ for the analysis as a whole are aquatic faunivores and carnivores, all obligate secondary consumers. The other faunal variables have indices between 0.47 and 0.66 on the first two axes. For some faunal variables, most of the explained variation lies on the (first) temperature axis (e.g. size class 1, aerial insectivores). For other variables, most of the explained variation lies on the (second) moisture-elevation axis (e.g. size class 5 , herbivores). For other variables (e.g. size class 6 , granivores), both environmental axes contribute substantially to the explained variation. These
Table II Redundancy index for each faunal variable individually, expressed as the cumulative fraction of the variance in the faunal variable explained on environmental Axes 1,2, and for the analysis as whole (total). Based on the redundancy analysis with five environmental variables and all faunal variables, Tables $9(\mathrm{~b})$ and 10(b), and Fig. 10(c,d).

\begin{tabular}{llll}
\hline Faunal variable & Axis 1 & Axis 2 & Total \\
\hline Size class 1 & 0.77 & 0.77 & 0.79 \\
Size class 2 & 0.77 & 0.77 & 0.77 \\
Size class 3 & 0.58 & 0.78 & 0.80 \\
Size class 4 & 0.55 & 0.57 & 0.68 \\
Size class 5 & 0.28 & 0.64 & 0.71 \\
Size class 6 & 0.36 & 0.55 & 0.65 \\
Aquatic faunivore & 0.13 & 0.14 & 0.30 \\
Carnivore & 0.12 & 0.31 & 0.49 \\
Aerial insectivore & 0.80 & 0.81 & 0.82 \\
Terrestrial invertivore & 0.47 & 0.47 & 0.57 \\
Omnivore & 0.70 & 0.75 & 0.79 \\
Frugivore & 0.52 & 0.66 & 0.67 \\
Granivore & 0.45 & 0.75 & 0.79 \\
Herbivore & 0.02 & 0.54 & 0.63 \\
\hline
\end{tabular}

patterns correspond to the distribution of faunal variables in the ordination diagrams (Fig. 10a,c).

Figure $10(b, d)$ shows quadrat scores in the ordination space of each redundancy analysis. Quadrats on the left side of the first axis represent regions with a high annual range of temperature, while quadrats on the right side depict areas with low seasonality of temperature and a long frostfree period. Quadrats in the upper right quadrant represent xeric regions with warm summers at higher elevations, including the Great Basin and Chihuahuan Desert. Quadrats in the lower right 
(a) Size class $1(0,44)$

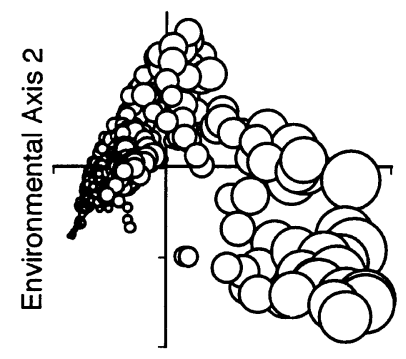

(c) Size class $3(0,28)$

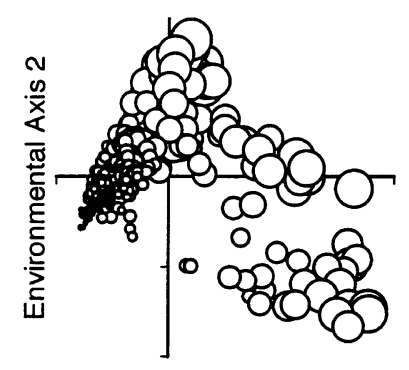

(e) Size class $5(2,13)$

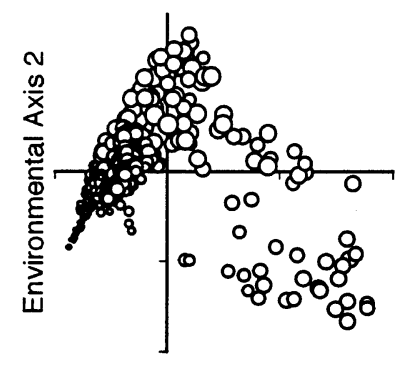

(g) Total species density $(13,198)$

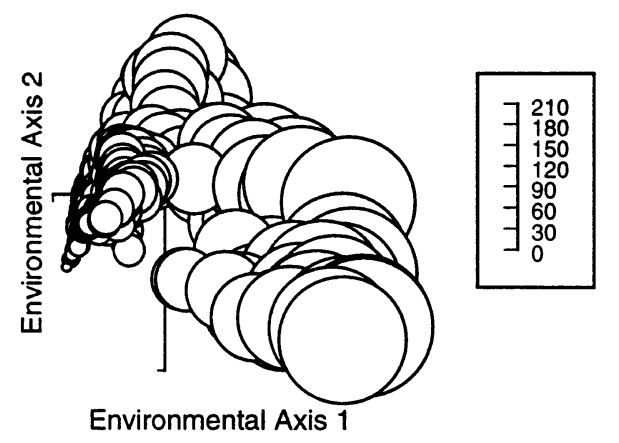

(b) Size class $2(5,92)$

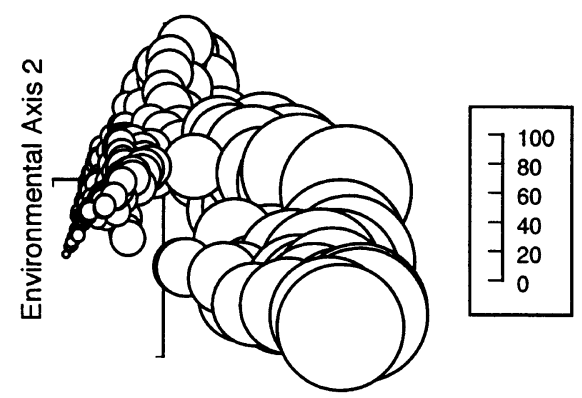

(d) Size class $4(3,29)$

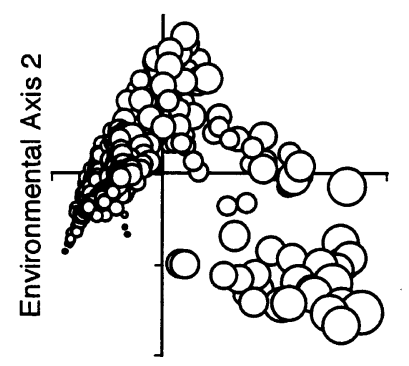

(f) Size class $6(0,7)$

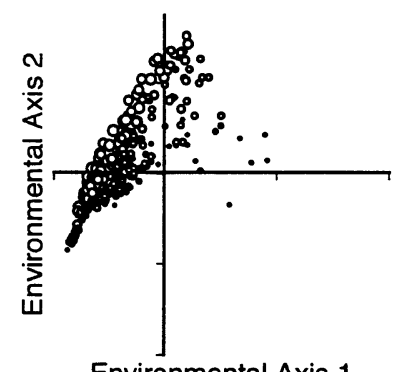

Environmental Axis 1
Figure I I The original data for size structure plotted as three-dimensional bubble diagrams in the ordination space of Fig. 10(c,d). Each size category is graphed separately to show how size categories vary over ordination space. All bubbles are plotted to the same scale in Fig. 11 (except Fig. 11g) and Fig. 12, for ease of comparison. The lowest and highest values of species density for each size category are given in parentheses above each graph. See text for explanation. (a) Size class 1, (b) size class 2, (c) size class 3, (d) size class 4, (e) size class 5, (f) size class 6. (g) Total species density plotted in the same ordination space for comparison; note different scale for this graph. quadrant depict the moist tropics. Quadrats in the lower left quadrant depict boreal to arctic regions at relatively low elevation. Quadrats in the upper left quadrant have intermediate values of seasonality of temperature and moisture, and represent moderate to high elevations.

Figures 11 and 12 depict the original faunal data in the ordination space of the reduced model for each size class and trophic category. The location of quadrats in the ordination diagram is given by the quadrat scores, and the bubble size indicates the frequency of species in each quadrat. Recall the geographical interpretation of the ordination diagram in Fig. 10(c). With the exception of Fig. 11(g), all graphs in Figs 11 and 12 have the same scaling, so that the size of the bubbles can be accurately compared within and among graphs. 
(a) Aerial insectivores $(0,62)$

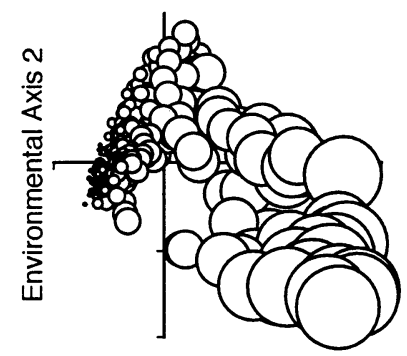

(c) Aquatic faunivores $(0,6)$

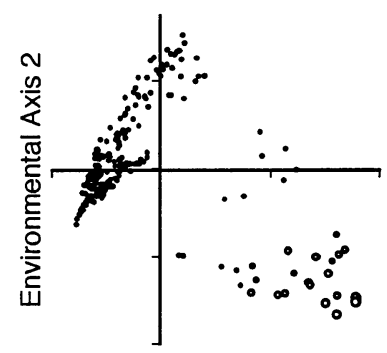

(e) Omnivores $(0,14)$

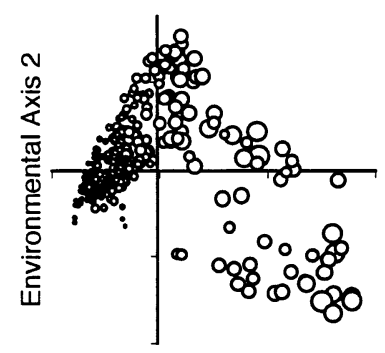

(g) Granivores $(0,38)$

structure plotted as bubble diagrams in the ordination space of Fig. 10(c-d). Each trophic category is graphed separately to show how they vary over ordination space. All bubbles are plotted to the same scale as in Fig. 11(a-f), for ease of comparison. The lowest and highest values of species density for each trophic category are given in parentheses above each graph. See text for explanation.

(a) Aerial insectivores, (b) terrestrial invertivores, (c) aquatic faunivores,

(d) carnivores, (e) omnivores, (f) frugivores, $(\mathrm{g})$ granivores, $(\mathrm{h})$ herbivores.

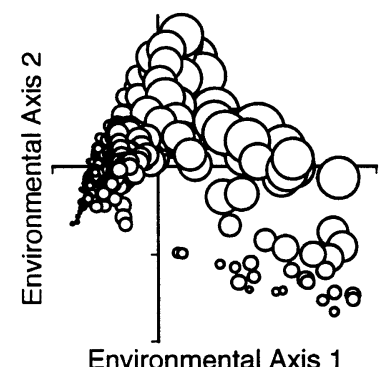

(b) Terrestrial invertivores $(0,20)$

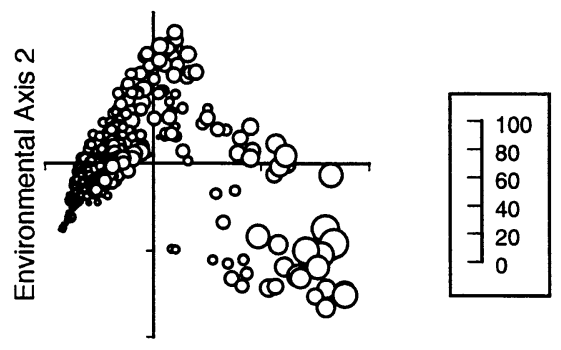

(d) Carnivores $(6,17)$

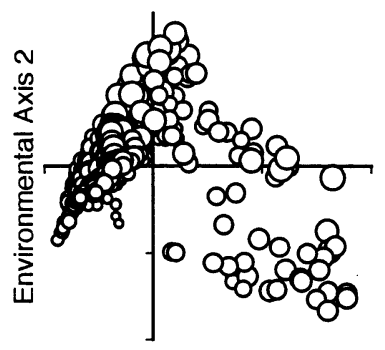

(f) Frugivores $(0,59)$

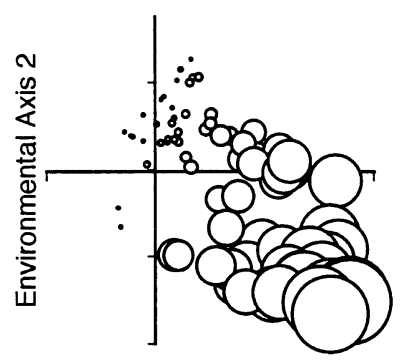

(h) Herbivores $(5,40)$

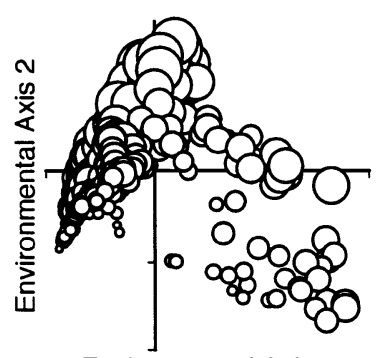

Environmental Axis 1
Fig. 11(g) shows total species density, although this variable was not included in the analysis. It is readily apparent that size classes 1-5 (Fig. 11a-e) are widely distributed in ordination space, but size class 6 (Fig. 11f) is absent from some of the upper and most of the lower right quadrants, representing warm deserts and the moist tropics. Size class 2 (Fig. 11b) shows the greatest variation in species density (from five to 92 species per quadrat), whereas size classes 5 and 6 (Fig. 11e,f) show relatively little variation among quadrats. Size classes 1, 2 and 4 reach the highest species density in the moist, warm tropics.
Size classes 3 and 5 show the highest density in the mountainous or desert quadrats of the upper right quadrant. Size class 6 has the highest values in quadrats with high seasonality of temperature.

Most trophic categories are represented by species throughout the ordination space (Fig. 12). Aquatic faunivores (Fig. 12c) are absent from a number of quadrats, representing xeric or mountainous regions, in the upper quadrants. Frugivores (Fig. 12f) are absent from all quadrats in regions with high seasonality of temperature (upper left quadrant) and from some 
xeric sites in the upper right quadrant also. Aerial insectivores (Fig. 12a), frugivores (Fig. 12f), granivores (Fig. 12g) and herbivores (Fig. 12h) show a wide range of species densities among quadrats, whereas carnivores (Fig. 12d) and omnivores (Fig. 12e) show a low range of variation. Aerial insectivores and frugivores reach their highest densities in the moist, warm tropics. So do terrestrial invertivores and omnivores at much lower species densities. Granivores reach their highest densities in deserts at relatively high elevations. Herbivores have the highest species densities in mountainous regions of intermediate seasonality of temperature.

Variation in total species density in the same ordination space (Fig. 11g) can be compared with the patterns for the individual size classes and trophic categories. Species density ranges from 17 to 187 species/quadrat. Species density is highest at sites in the lower right quadrant, representing the moist, warm tropics, where species in size classes 1, 2 and 4, aerial insectivores, terrestrial invertivores, omnivores and frugivores are most numerous. Intermediate species densities prevail in dry regions (upper right quadrant), where species in size classes 3 and 5, aerial insectivores, granivores and herbivores are numerous. Species density is lowest in boreal and arctic quadrats (left side of first axis), where species in size class 6, carnivores and herbivores are relatively numerous.

\section{DISCUSSION}

This survey shows that species density and the ecological structure of mammalian faunas change along environmental gradients of climate and physiography. Five environmental variables, representing seasonal extremes of temperature, annual energy and moisture, and topography predict $88 \%$ of the variation in species density across North America (Table 4a). While the latitudinal gradient in mammalian species richness is strong (Fig. 6a), little of it remains after the effects of environmental variables on species richness are accounted for (Fig. 6b). The environmental variables explain most of the spatial structure in species density (Figs $5 \& 6 \mathrm{c}$ ). The variables that predict species density well vary among different regions of the continent (Table 6), suggesting that there are multiple faunal-environmental relationships present over North America.

A slightly different set of environmental variables, representing winter temperature, frostfree period, moisture demand, moisture availability and elevation, accounts for $76 \%$ of the variation in the ecological structure of mammalian faunas (Table 9b). The environmental variables are more successful at predicting some faunal variables than others (Table 11). For species in size classes 1,2, 3 and 5, aerial insectivores, omnivores and granivores, the environmental variables explain over $70 \%$ of the variation in faunal data. For aquatic faunivores and carnivores, the environmental variables explain less than half the variation. While species in most ecological categories occur over a wide range of environmental conditions and in many biomes, each ecological category peaks in species richness for particular environmental conditions (Figs $11 \& 12$ ).

From these results, we can address the five research questions posed earlier.

\section{(I) Which environmental variables predict a high proportion of the variation in species density and ecological structure of North American mammals?}

These environmental variables were identified by regression analysis for species density and by redundancy analysis for ecological structure. The most satisfactory regression model (Table 4a) contained annual minimum temperature, annual maximum temperature, annual AET, relief and elevation. The most satisfactory redundancy analysis included annual minimum temperature, frostfree period, annual PET, annual AET and elevation. The two sets of variables are not identical, although they have three variables in common. Annual minimum temperature and annual PET show strong latitudinal gradients (Fig. 3). Annual AET, relief and elevation show weak longitudinal gradients (Fig. 4). The effects of these variables on species density and ecological structure are described under (4) below.

\section{(2) Does the predictive ability of energy variables and topography, as documented by Currie (1991) and Kerr \& Packer (1997) for Canada and USA, persist when data for the entire continent are analysed?}

There are both similarities and differences between our results and those of these earlier studies. In both earlier studies, annual PET and relief were found to be important predictors of mammalian species density. In our results, PET is not significant in multiple regression with other environmental variables over the entire continent, but is significant for most geographical subsets, including the region analysed by Currie (quadrats $>30^{\circ} \mathrm{N}$, Table 6a). Relief contributed significantly to our multiple regression models for all regions evaluated except the temperate region (Table 6b). These results do not contradict the energy hypothesis of Currie (1991), Wright, Currie \& Maurer (1993) and others, since other climatic variables indicative of local energy (temperature, AET) were present in the most satisfactory regression and redundancy analyses. However, seasonality of temperature was important to all our results, suggesting that seasonality per se is an important climatic influence.

\section{(3) How does the relationship between mammalian species density and environmental variables change in different geographical regions of North America?}

Our results and the differences with the two earlier studies mentioned earlier underscore the geographical variation in the relationship between environmental conditions and species density, as well as ecological structure. Kerr \& Packer (1997) showed that PET and relief each predicted species density well in different regions. In the present study, environmental variables with a positive effect on species density in boreal regions are annual maximum temperature, annual PET and relief or elevation (Table 6a,b). In subtropical regions, annual minimum temperature, annual AET, elevation and relief have significant positive effects on species density. In the temperate region, a different set of environmental variables is significant. The 
same six environmental variables have significant effects on species density in eastern and western North America, but annual PET has a negative effect in the eastern half and a positive effect in the western half (Table $6 \mathrm{~b}$ ). The redundancy analysis also shows that the environmental variables establish correlated but distinctive gradients in different regions of ordination space (Fig. 10b) and continental geography (Fig. 10c).

\section{(4) How does environmental variation influence the kinds as well as numbers of mammal species in North America?}

Where annual minimum temperature is high, species richness and the frequency of species in size classes 1,2 and 4, aerial insectivores, omnivores and terrestrial invertivores are high. Where annual minimum temperature is low and the frostfree period is short, species richness is low, and species of size class 6 are more numerous than elsewhere. Where annual maximum temperature is high, annual PET also tends to be high; species of size classes 3 and 5, granivores, and carnivores are more numerous than they are under different environmental conditions. Where annual AET is high, annual precipitation is also high and winters are warm. Total species richness and species of frugivores, aerial insectivores, and size classes 1, 2 and 4 reach their highest frequencies. When climatic conditions are held constant at the scale of the quadrats, species richness tends to increase with elevation and relief.

\section{(5) Are particular ecological categories of mammals predicted better by particular environmental variables?}

Some ecological categories are predicted much better than others by the redundancy analysis as a whole (Table 11). For all but two categories, the environmental variables predict $>55 \%$ of the variance in the faunal data. The changes of greatest magnitude involve the two smallest size categories (<10 g, 11-100 g), aerial insectivores and frugivores (Figs 11 $\& 12)$. Species in these categories, mostly bats, increase along a gradient of decreasing winter temperature and increasing annual moisture and frostfree period, trends that are correlated with latitude. At the opposite end of this gradient, species in the largest size category $(101-1000 \mathrm{~kg}$ ) increase in frequency. Species in size categories $3(101-1000 \mathrm{~g}), 5(11-100 \mathrm{~kg})$ and 6 (101-1000 kg), herbivores and granivores increase along a longitudinal gradient of increasing annual PET and elevation. In Table 11, the partitioning of explained variance between Axes 1 and 2 indicates that the variables strongly correlated with Axis 1 (annual minimum temperature, frostfree period, PET and AET) predict better the size classes 1, 2, 3 and 4, and the trophic categories aerial insectivore, terrestrial invertivore, omnivore and frugivore. The variables correlated with Axis 2 (elevation, PET, and to some extent AET) predict better size class 5 and herbivores. Size class 6 and granivores have subequal contributions from both sets of variables. Aquatic faunivores and carnivores are predicted poorly by the environmental variables.

\section{Biogeographical factors}

Changes in mammalian species density do not simply involve an increase or decrease in species from all size and trophic categories in concert. In some ecological categories, species increase in frequency toward areas of low seasonality of temperature and high annual precipitation. In other categories, species increase toward regions of high PET, high elevation and low precipitation. Species in the largest size class increase under high seasonality of temperature. This result is not surprising from the standpoint of earlier literature about the zoogeography of North American mammals. For example, Hagmeier \& Stults (1964) and Jones \& Birney (1988) documented the affiliation of particular mammals for regions that are distinctive in physiography, vegetation and macroclimate.

Several factors must be considered as potential causes of these gradients in the ecological structure of mammalian faunas. The first is ecological sorting of species according to their environmental tolerances through geographical-range shifts in response to changes in environmental conditions. In several respects, North American mammals show evidence of ecological sorting. First, late Quaternary, North American mammals experienced substantial geographical-range shifts in an individualistic pattern, during an interval of rapid climatic changes at the end of the Pleistocene (Graham \& Mead, 1987; Graham et al., 1996). These data show that mammalian species ranges can respond rapidly to environmental changes. However, it is not known whether the pattern of late Pleistocene or earlier shifts parallels the pattern of ecological structure in relation to environmental gradients seen today. Second, in this century, some mammalian range extensions appear to be limited by temperature or precipitation (e.g. Taulman \& Robbins, 1996). Third, the data presented here suggest the presence of environmental thresholds for species with particular ecological attributes. The clearest example is the frequency of frugivores in relation to both temperature and moisture gradients (Figs $8 \mathrm{f}$ $\&$ 9f). No other ecological group in Figs 8 and 9 shows such a striking pattern, but abrupt changes in slope (as in Fig. 8a,j,l) suggest discontinuous relationships between climatic conditions and the frequency of species with certain ecological attributes. These aspects of faunal structure are consistent with ecological sorting processes. Also, Porter et al. (1996), using principles of thermal physiology, modelled changes in the optimal body size of mammals in relation to climatic gradients. Their results are in general agreement with the variation in mammalian size distributions reported here, and support the concept of ecological sorting according to physiological tolerances. Andrews \& O'Brien (2000) found similar relationships to those reported here between seasonality of temperature and topographical relief with mammalian species richness of southern Africa; different ecological guilds of South African mammals were strongly correlated with different environmental variables.

But some aspects of the patterns presented here are not consistent with ecological sorting. For example, in several ecological categories (aerial insectivores, size classes 1, 2, 3 and others), species increase in frequency as precipitation increases 
from north to south, but also increase as precipitation decreases from east to west (Figs $8 \& 9$ ). This pattern could mean that climatic moisture is an unimportant environmental variable for mammalian ecological diversity-an unlikely scenario. Alternatively, other factors interact with the gradients in moisture, such as the combined effects of moisture with temperature, evapotranspiration, elevation or variables not included in this study.

Other potential factors are time lags and barriers in ecological sorting processes. Time lags could arise from differences in the dispersal rates of species or filters across barriers that arise during an interval of substantial dispersal. The result is areas with lower species density than environmental conditions can now potentially support. Evidence against time lags is that mammalian species ranges within the USA have changed relatively little over the last 8000 years, according to the extensive fossil record of late Quaternary mammals (Graham \& Mead, 1987). But the late Quaternary record is not as well documented for Canada or Mexico and Central America. In principle, time lags could be evaluated by studying dispersal patterns and rates through the late Quaternary. South-eastern USA is anomalously depauperate in mammal species and seems to be missing kinds of species that could readily be supported from the standpoint of climate and vegetation. Species density ranges from 40 to 60 species per quadrat in the mesic, south-eastern, coastal plain, compared with values twice that high in arid western quadrats at the same latitude (Fig. 2). Curiously, frugivores are nonexistent. The number of species of herbivores and granivores is lower than expected for an area with the highest tree diversity in USA and Canada combined (Currie \& Paquin, 1987). A possible explanation for this anomaly is a barrier to the dispersal of potential colonists. During the last glaciation, species currently inhabiting southeastern USA either remained there during glacial advances or were displaced southward into Mexico and Central America. Possibly, after deglaciation, few species from mesic areas in eastern Mexico and Central America were able to disperse across the Chihuahuan Desert, a region which became xeric in the early Holocene (Van Devender, Thompson \& Betancourt, 1987), leaving the south-eastern USA isolated from a potential source of colonists. Pielou (1994) cites examples of rodent species that extended their ranges eastward as the last of the Laurentian ice sheet melted and were blocked by Hudson Bay from colonizing northern Quebec.

Another factor potentially influencing geographical variation in the number and kinds of species is evolutionary processes acting over time scales longer than the last few millenia. Rates of speciation and extinction vary among clades and regions. If either taxa or regions experienced sustained high speciation rates, then high species density, as well as high representation of species in a particular ecological category, could have a component that is related only indirectly to ecological sorting. Such circumstances probably pertain to the mountainous regions of western North America. Areas of high relief typically have strong elevational zonation of habitats; this zonation is the major reason for increased species density in mountainous regions at the scale of this study. As climatic conditions changed over geological time, environments expanded or contracted during shifts along an elevational gradient. The resulting changes in area, shape and elevation of species ranges provided numerous opportunities for vicariance (Cracraft, 1985; Vrba, 1995). These circumstances should have enhanced the probability of allopatric speciation, especially for species with relatively small individual home ranges. Species density is higher in western North America than in the eastern part at a given latitude, despite harsher climates in the west. Western North America is fragmented into many basins and mountain ranges. There, numerous species of congeneric rodents (e.g. Spermophilus and Dipodomys) occur with their closest relatives in adjacent mountain ranges or deserts, and there is high spatial turnover among rodent species. By contrast, in the eastern USA, species density is lower and more homogeneous across a broad region of low relief. Much of the relief of the Basin and Range of the western USA developed in the last $10 \mathrm{Ma}$, whereas the eastern USA has been tectonically stable since the Jurassic.

Extinction rates were probably higher over the last $2.5 \mathrm{Ma}$ in glaciated regions than in unglaciated regions of North America, because of the sheer magnitude of habitat destruction. The numerous glacial advances and retreats of the current Ice Age may have favoured persistence of species with broad environmental tolerances and good dispersal capabilities. Also, late Pleistocene extinction may have biased the full expression of faunal structure in relation to climatic conditions in North America. Pleistocene glaciations caused repeated local extinctions but few global extinctions of mammals until the end of the Pleistocene. Most mammal species that became extinct were over $5 \mathrm{~kg}$ in body mass; all species over $1000 \mathrm{~kg}$ and three-fourths of herbivore genera between 101 and $1000 \mathrm{~kg}$ (size class 6) became extinct by about 10,000 yr вр (Owen-Smith, 1988). Causes of this extinction episode are controversial. Hypotheses include rapid environmental change (e.g. Grayson, 1991), human overkill (Martin, 1984) and human overkill of herbivores greater than $1000 \mathrm{~kg}$, followed by cascading indirect effects for other species (Owen-Smith, 1988). If these large mammals had not become extinct, the latitudinal gradient in species density would differ slightly from the current pattern, and the pattern of faunal structure in relation to climatic conditions would differ for the largest mammals (and for herbivores). Species of a larger size class (>1000 kg) than is now present would be widely distributed, and more species of size class 6 would occur at low latitudes, as they did in the late Pleistocene (e.g. Janzen \& Martin, 1982).

The influence of all these factors is not easy to test. A strong role for evolutionary processes would be supported by evidence of speciation or extinction covarying with the variables underlying the major environmental gradients. A dense fossil record of Neogene mammals could indicate whether modern areas of endemism represent contractions of formerly larger geographical ranges or regions of elevated speciation rates. The geography of speciation and extinction, as revealed by phylogenetic analysis of extant and extinct taxa from the same group along with a dense fossil record, could indicate whether speciation or extinction rates varied significantly among macroclimatically different regions. Evolutionary processes would be unimportant if speciation and extinction rates were found to be uniform or random with respect to geography or taxa. Also, the correlation between ecological attributes and phylogeny needs to be 
evaluated; our analysis treated the attributes of each species as statistically independent of the attributes of other species, but this is not strictly correct.

The patterns presented here for the ecological structure of North American mammals represent a time slice of the last few hundred years and do not offer tests of the factors mentioned above. Evaluation of these would ideally require detailed records of faunal and environmental changes over the last few million years, phylogenies for the more diverse clades, and comparative data for other continental regions. It is plausible that all the factors mentioned, operating over different temporal and spatial scales, have contributed to the modern gradients in mammalian ecological diversity.

\section{CONCLUSION}

Changes in the species density of mammalian faunas across North America are accompanied by changes in ecological diversity, as depicted by size structure and trophic structure. A high proportion of the variation in species density and ecological structure of mammalian faunas can be explained by climatic and physiographical variables. Different ecological categories exhibit their greatest species density under different environmental conditions (Figs 10-12). Aspects of ecological structure that change most over North American gradients in climatic temperature, moisture and topography are the frequency of species in the three smallest size classes $(\leq 10 \mathrm{~g}, 11-100 \mathrm{~g}$ and $101-1000 \mathrm{~g}$ ) and the trophic categories of aerial insectivore, omnivore, frugivore and granivore (Table 11, Figs $11 \& 12$ ). Aspects of ecological structure that change least are the frequency of species in the largest size class $(101-1000 \mathrm{~kg}$ ) and in the trophic categories of aquatic faunivore, carnivore, terrestrial invertivore and herbivore. Environmental variables correlated with the greatest changes in ecological structure are annual minimum temperature, frostfree period, annual PET and AET, and elevation. Changes in overall species density are dominated by increases in smaller species, aerial insectivores, frugivores and terrestrial invertivores from north to south and by increases in medium-sized to large species, granivores and herbivores from east to west. The largest species are more numerous at high latitudes.

Most of the proposed causes of geographical gradients in species density would not be expected to act equivalently on all species of mammals (or any other major group). Whether the causes entail sorting of species ranges according to their physiological tolerances of environmental conditions, variation in speciation or extinction rates among taxa and regions, or barriers to dispersal across a heterogeneous landscape, the species affected should respond differently depending on their life-history traits, population size, resource requirements and other ecological attributes. Many such attributes are correlated with body size. Emphasis on ecological structure (rather than number of species alone) permits a sharpening of hypotheses about the effects of particular environmental variables on the ecological and evolutionary processes that shape the composition of communities. Data from other continents as well as from the late Cenozoic record of mammals and palaeoclimates should help to clarify these relationships.

\section{ACKNOWLEDGMENTS}

We thank the staff of the American Philosophical Society in Philadelphia for making available documents from the archives of G. G. Simpson, L. Farber for high standards in data entry, the staff of the University of Michigan map library for assistance in finding climatic maps and B. Miljour for work on illustrations. We also thank R. Furnas and C. ter Braak for clarification of statistical methods and T. McDaniel for advice with regression analysis. We benefited from discussions with G. R. Smith and from comments of J. H. Brown, J. Damuth, T. Baumiller and anonymous reviewers. This work was partly supported by a grant from the National Science Foundation.

\section{REFERENCES}

Andrews, P. \& O'Brien, E. (2000) Climate, vegetation, and predictable gradients in mammal species richness in southern Africa. Journal of Zoology, 251, 205-231.

Anonymous (1985) The Times atlas of the world, 7th edn. Times Books Limited, London.

ter Braak, C. J. F. \& Smilauer, P. (1998) CANOCO reference manual and user's guide to CANOCO for Windows: software for canonical community ordination, version 4, Microcomputer Power, Ithaca, NY.

Brown, J. H. \& Lomolino, M. V. (1998) Biogeography, 2nd edn. Sinauer, Sunderland, MA.

Cox, C. B. \& Moore, P. D. (1985) Biogeography: an ecological and evolutionary approach, 4th edn. Blackwell, Oxford.

Cracraft, J. (1985) Biological diversification and its causes. Annals of the Missouri Botanic Gardens, 72, 794-822.

Currie, D. J. (1991) Energy and large-scale patterns of animaland plant-species richness. American Naturalist, 137, 27-49.

Currie, D. J. \& Paquin, V. (1987) Large-scale biogeographical patterns of species richness of trees. Nature, 329, 326-327.

Damuth, J. \& MacFadden, B. J., eds (1990) Body size in mammalian paleobiology: estimation and biological implications, Cambridge University Press, Cambridge.

Eisenberg, J. F. (1981) The mammalian radiations, University of Chicago Press, Chicago, IL.

Energy, Mines and Resources Canada. (1981) Canada-frost-free period (map). The national atlas of Canada, 5th edn. Geographical Services Directorate, Department of Energy, Mines and Resources, Ottawa.

Gittins, R. (1985) Canonical Analysis, Springer-Verlag, Berlin.

Graham, R. W., Lundelius, E. L. Jr, Graham, M. A., Schroeder, E. K., Toomey, R. S. III, Anderson, E., Barnosky, A. D., Burns, J. A., Churcher, C. S., Grayson, D. K., Guthrie, R. D., Harrington, C. R., Jefferson, G. T., Martin, L. D., McDonald, H. G., Morlan, R. E., Semken, H. A. Jr, Webb, S. D., Werdelin, L. \& Wilson, M. C. (1996) Spatial response of mammals to late-Quaternary environmental fluctuations. Science, 272, 1601-1606.

Graham, R. W. \& Mead, J. I. (1987) Environmental fluctuations and evolution of mammalian faunas during the last deglaciation in North America. North America and adjacent oceans during the last deglaciation (ed. by W. F. Ruddiman and H. E. Wright, Jr), pp. 371-402. Geological Society of America, Boulder, CO.

Grayson, D. K. (1991) Late Pleistocene mammalian extinctions in North America: Taxonomy, chronology, and explanations. Journal of World Prehistory, 5, 193-231. 
Gujarati, D. N. (1995) Basic econometrics, 3rd edn. McGraw-Hill, New York, NY.

Hagmeier, E. M. \& Stults, C. D. (1964) A numerical analysis of the distributional patterns of North American mammals. Systematic Zoology, 13, 125-155.

Hall, E. R. (1981) The mammals of North America, 2nd. edn. John Wiley, New York, NY.

Hamilton, L. C. (1992) Regression with graphics: a second course in applied statistics. Duxbury Press, Belmont, CA.

Huston, M. (1995) Biological diversity. Cambridge University Press, Cambridge.

Instituto Panamericano de Geografia e Historia. (1976) Atlas climatológico e hidrológico del istmo Centroamericano, atlas with eight maps. Publication no. 367, Pan American Institute of Geography and History, Guatemala.

Janis, C. (1997) Ungulate teeth, diets, and climatic changes at the Eocene/Oligocene boundary. Zoology, 100, 203-220.

Janzen, D. H. \& Martin, P. S. (1982) Neotropical anachronisms: The fruits the gomphotheres ate. Science, 215, 19-27.

Jones, J. K. \& Birney, E. C. (1988) Handbook of mammals of the north-central states, University of Minnesota Press. Minneapolis, MN.

Jongman, R. H. G., ter Braak, C. J. F. \& Tongeren, O. F. R. (1995) Data analysis in community and landscape ecology, Cambridge University Press, Cambridge.

Kerr, J. T. \& Packer, L. (1997) Habitat heterogeneity as a determinant of mammal species richness in high-energy regions. Nature, 385, 252-254.

Legendre, S. (1989) Les communautés de mammifères du Paléogène (Eocène supérieur et Oligocène) d'Europe occidentale: structures, milieux, et évolution. Münchner Geowissenschaftliche Abhandlungen, Reihe A, Geologie und Paläontologie, $16,110 \mathrm{p}$.

Martin, P. S. (1984) Prehistoric overkill: The global model. Quaternary extinctions (ed. by P. S. Martin and R. G. Klein), pp. 354-403. University of Arizona Press, Tucson.

McNab, B. K. (1990) The physiological significance of body size. Body size in mammalian paleobiology (ed. by J. Damuth and B. J. MacFadden), pp. 11-23. Cambridge University Press, Cambridge.

Montgomery, D. C. \& Peck, E. A. (1982) Introduction to linear regression analysis. John Wiley, New York, NY.

Nowak, R. M. (1991) Walker's mammals of the world, 5th edn. Johns Hopkins University Press, Baltimore, MD.

Oliver, J. E. (1987) Evapotranspiration. The encyclopedia of climatology (ed. by J. E. Oliver and R. W. Fairbridge), pp. 449-456. Van Nostrand Reinhold Co., New York, NY.

Owen-Smith, R. N. (1988) Megaherbivores. Cambridge University Press, Cambridge.

Pielou, E. C. (1994) A naturalist's guide to the arctic. University of Chicago Press, Chicago, IL.

Porter, W. P., Hopp, M., Ramankutty, N. \& Foley, J. (1996) Climate variation and optimal body sizes: Implications for community structure globally. Bulletin of the Ecological Society of America, 77 (Suppl. to No. 3), 358.

Ricklefs, R. E. \& Schluter, D., eds (1993) Species diversity in ecological communities. University of Chicago Press, Chicago, IL.

Rosenzweig, M. L. (1968) Net primary production of terrestrial communities: Prediction from climatological data. American Naturalist, 102, 67-74.
Rosenzweig, M. L. (1992) Species diversity gradients: We know more and less than we thought. Journal of Mammalogy, 73, $715-730$.

Rosenzweig, M. L. (1995) Species diversity in space and time. Cambridge University Press, Cambridge.

Simpson, G. G. (1964) Species density of North American Recent mammals. Systematic Zoology, 13, 57-73.

Sokal, R. R. \& Oden, N. L. (1978) Spatial autocorrelation in biology. 1. Methodology. Biological Journal of the Linnaean Society, 10, 199-228.

Sokal, R. R. \& Rohlf, F. J. (1981) Biometry, 2nd edn. W. H. Freeman, New York, NY.

Sokal, R. R. \& Thomson, J. D. (1987) Applications of spatial autocorrelation in ecology. Developments in numerical ecology (ed. by P. Legendre and L. Legendre), pp. 431-466. SpringerVerlag, Berlin.

Stucky, R. K. (1990) Evolution of land mammal diversity in North America during the Cenozoic. Current mammalogy, Vol. 2 (ed. by H. H. Genoways), pp. 375-432. Plenum, New York, NY.

Taulman, J. F. \& Robbins, L. W. (1996) Recent range expansion and distributional limits of the nine-banded armadillo (Dasypus novemcinctus) in the United States. Journal of Biogeography, 23, 635-648.

United States Department of Commerce (Environmental Science Services Administration) (1968) Climatic atlas of the United States. US Government Printing Office, Washington, DC.

Universidad Nacional Autónoma de México, Instituto de Geografia. (1991) Atlas Nacional de México. La Universidad, Mexico City.

USSR National Committee for the International Hydrological Decade. (1977) Atlas of world water balance. Unesco, Paris.

Van Devender, T. R., Thompson, R. S. \& Betancourt, J. L. (1987) Vegetation history of the deserts of southwestern North America: The nature and timing of the Late Wisconsin-Holocene transition. North America and the adjacent oceans during the last deglaciation (ed. by W. F. Ruddiman and H. E. Wright, Jr), pp. 323-352. Geological Society of America, Boulder, CO.

Vrba, E. S. (1995) On the connections between paleoclimate and evolution. Paleoclimate and evolution with emphasis on human origins (ed. by E. S. Vrba, G. H. Denton, T. C. Partridge and L. H. Burckle), pp. 24-45. Yale University Press, New Haven, CT.

Ward, R. de C., Brooks, C. F. \& Connor, A. J. (1936) The climates of North America. Handbuch der Klimatologie, Band II, Teil J. Verlag von Gebrüder Borntraeger, Berlin.

Wartenburg, D. (1989) SAAP-A spatial autocorrelation analysis program (manual and software).

Webb, S. D. (1989) The fourth dimension in North American terrestrial mammal communities. Patterns in the structure of mammalian communities (ed. by D. W. Morris, Z. Abramsky, B. J. Fox and M. R. Willig), pp. 181-203. Spec. Publication no. 28. Texas Tech University Press, Lubbock, TX.

Weisberg, S. (1985) Applied linear regression, 2nd edn. John Wiley, New York, NY.

Whittaker, R. H. (1975) Communities and ecosystems, 2nd edn. Macmillan, New York, NY.

Wilson, D. E. \& Reeder, D. M. (1993) Mammal species of the world, 2nd edn. Smithsonian Institution Press, Washington, D.C.

Wright, D. H., Currie, D. J. \& Maurer, B. M. (1993) Energy supply and patterns of richness on local and regional scales. Species diversity in ecological communities (ed. by R. E. Ricklefs and D. Schluter), pp. 66-73. University of Chicago Press, Chicago, IL. 


\section{Appendix I Guidelines for reducing the number of environmental variables in regression and canonical analyses}

Nested F-test

The nested $F$-test is a method of comparing the statistical significance of different sets of independent variables in related regression models with the same dependent variable. The test works by comparison of the sum of squared errors (SSE), appropriately adjusted for degrees of freedom, of two regression models. If model 1 contains a full set $k$ of possibly useful independent variables and model 2 contains a reduced set $(k-j)$ of independent variables, then the quantity

$$
\frac{\left(\mathrm{SSE}_{2}-\mathrm{SSE}_{1}\right) / j}{\mathrm{SSE}_{1} / \mathrm{d}_{\mathrm{f}} ._{1}}
$$

where $j=$ d.f. $._{1}-$ d.f.f. $\left(\right.$ d.f. $=$ degrees of freedom) has an $F^{j \text { d.f.f.1 }}$ distribution (Gujarati, 1995).

In this study, the full model has the lowest SSE, but some of the regression coefficients are non-significant and the measures of multicollinearity are excessively high for several variables (Appendix 2). Our goal was to construct a regression model with a subset of environmental variables that had no significant reduction in SSE relative to the full model. To this end, we used three stages to arrive at the 'best' model that was both ecologically and statistically sound.

First, we hypothesized that the temperature variables, the moisture variables and the topography variables each mattered as a group to the prediction of species density. To test this hypothesis, we determined the full regression model with all nine environmental variables (Appendix 2); this model served as model 1 in all nested $F$-tests. Then we omitted each group of variables, one group at a time, to determine if its omission significantly increased the SSE of the reduced model. This required three comparisons: (1) full model vs. reduced model without any temperature variables, (2) full model vs. reduced model without any moisture variables, and (3) full model vs. reduced model without any topography variables.

Results of these tests are as follows. (1) Full model (includes all nine environmental variables) vs. reduced model (omits annual range of temperature, annual minimum temperature, annual maximum temperature, frostfree period). $\mathrm{SSE}_{1}=13.07 ; \mathrm{SSE}_{2}=15.54$. For $P=0.01$, $F^{4,378} \approx 3.36$; the calculated ratio was 17.85 . Since $F_{\text {observed }} \gg F_{\text {critical }}$, the temperature variables are significant to the regression model. (2) Full model vs. reduced model (omits annual precipitation, annual PET and annual AET). (PET can be grouped with either the temperature variables or moisture variables; we did both and the results of the $F$ test were the same.) $\mathrm{SSE}_{1}=13.07 ; \mathrm{SSE}_{2}=15.96$. Following the logic explained for (1), for $P=0.01, F^{3,378} \approx 3.83$; the observed ratio was 27.8. Since $F_{\text {observed }} \gg F_{\text {critical }}$, the moisture variables are significant to the regression model. (3) Full model vs. reduced model (omits relief and elevation). $\mathrm{SSE}_{1}=13.07 ; \mathrm{SSE}_{2}=23.70$. Following the logic explained for (1), for $P=0.01, F^{2,378}=4.66$; the observed ratio was 153.61. Since $F_{\text {observed }} \gg F_{\text {critical }}$, the topography variables are significant to the regression model. These tests demonstrate that each of the three groups of variables contributes significantly to the regression model by reducing the errors in the predicted values of species density.

The second stage was to determine within each group of variables which ones could be removed without significantly reducing the SSE of the full model. For each group, we calculated the auxiliary $R^{2}$ of each variable with the other variables in the group. The auxiliary $R^{2}$ measures the amount of variation in one independent variable explained by the other variables; hence, especially high values of the auxiliary
$R^{2}$ indicate a high redundancy of that variable with the other variables present. Appendix 3 presents the auxiliary $R^{2}$ values for each independent variable in relation to selected relevant other environmental variables. The point of this exercise was to determine which variable(s) from each group would best represent the information in the whole group of variables in a multiple regression model. This stage yielded one or two variables in each group that had relatively low auxiliary $R^{2}$ values in relation to other variables present in the model.

The third stage involved testing various reduced models, guided by the examination of auxiliary $R^{2}$ values in Appendix 3, relative to the full model via nested $F$-tests. The goal was to identify a reduced model with a low SSE, independent variables from all three groups of environmental variables and significant regression coefficients for all independent variables. First, we omitted annual range of temperature and frostfree period and then performed the $F$-test. For $P=0.01$, $F^{2,378} \approx 4.66$; the observed ratio was 1.40 , implying that the omission of these variables did not significantly diminish the SSE. Next, we variously omitted annual minimum temperature, annual maximum temperature, annual PET, annual AET and annual precipitation, one or two at a time. In all models, we kept relief and elevation. The results of the $F$-tests indicated that the regression model in Table $4 \mathrm{a}$, with four fewer variables than the full model, had insignificantly different SSE than the full model. For $P=0.01, F^{4,378} \approx$ 3.36; the observed ratio was 1.30 . Further omissions significantly increased the SSE and thereby degraded the prediction of species density. The model in Table $4 \mathrm{~b}$, with six environmental variables, also has an SSE insignificantly different than that of the full model. For $P=0.01, F^{3,378} \approx 3.83$; the observed ratio was 1.54 . But this reduced model has high multicollinearity among three of its variables (annual minimum temperature, annual maximum temperature and annual PET); for this reason, the regression coefficient of PET is non-significant.

For the reasons outlined above, we selected the regression model with annual minimum temperature, annual maximum temperature, annual AET, relief and elevation (Table $4 \mathrm{a}$ ) as the best model to predict species density.

Forward selection of environmental variables and Monte Carlo permutation tests of significance in canonical ordination

The 'forward selection of environmental variables' (Table 8 ) is a procedure in CANOCO that allows selective addition of environmental variables to a canonical analysis. Before each variable is added, the significance of its contribution to the $R^{2}$ of the new analysis can be assessed through a Monte Carlo permutation test of the F-ratio. The test works by randomly changing sample numbers in the environmental data, so that the environmental data become assigned to the faunal data at random. This procedure generates a randomized set of faunalenvironmental associations for 199 (or more) new datasets; a redundancy analysis is produced for each randomized dataset. If the $F$-ratio for the actual data is greater than the $P$-value (in percentage) for the highest values of the $F$-ratio for 199 randomized datasets, then the analysis is considered significant at the selected $P$-value (ter Braak \& Smilauer, 1998). For example, if the $F$-ratio from the actual data is $\geq 5 \%$ of the highest $F$-values of first axes for the randomized datasets, then the analysis with the actual data is considered significant at the 0.05 level. In the results reported in Table $8 \mathrm{~b}$, the significance level was $P \leq 0.01$. We used the results of forward selection of environmental variables and the Monte Carlo significance test to help select a reduced set of environmental variables for redundancy analysis (see Table $9 b)$. 
Appendix 2 Regression model with all environmental variables, considered the full model for comparisons involving nested $F$-tests. At this stage of analysis, outliers were not omitted

Regression model

Species density $=-61.04-1.84($ annual range temperature $)+1.80($ annual minimum temperature $)+11.04($ annual maximum temperature $)+$ 0.03 (frostfree period) - 0.06 (annual precipitation) -0.09 (annual PET) +0.32 (AET) +0.07 (relief) +0.18 (elevation) + error; $n=388$

Regression diagnostics

$R^{2}=0.87$

Adjusted $R^{2}=0.87, \mathrm{P}=0.000000$

Standard error of regression $=0.186$

SSE $=13.07$, d.f. $=378$

\begin{tabular}{lccr}
\hline Independent variable & Coefficient & $\begin{array}{l}\text { Standard error } \\
\text { of coefficient }\end{array}$ & $P$-value \\
\hline Annual range of temperature & -1.844 & 1.155 & 0.1111 \\
Annual minimum temperature & 1.799 & 0.645 & 0.0055 \\
Annual maximum temperature & 11.038 & 1.871 & 0.0000 \\
Frostfree period & 0.026 & 0.042 & 0.5326 \\
Annual precipitation & -0.064 & 0.037 & 0.0839 \\
Annual PET & -0.088 & 0.069 & 0.1998 \\
Annual AET & 0.322 & 0.048 & 0.0000 \\
Relief & 0.065 & 0.016 & 0.0001 \\
Elevation & 0.184 & 0.0000 \\
\hline
\end{tabular}

PET, potential evapotranspiration; AET, actual evapotranspiration.

Appendix 3 Auxiliary $R^{2}$ values for selected subsets of environmental variables. The auxiliary $R^{2}$ is the $R^{2}$ of the multiple regression of one environmental variable on other environmental variables; the auxiliary $R^{2}$ expresses the amount of variation in one environmental variable explained by the other environmental variables. The ideal is to have a set of independent variables with low auxiliary $R^{2}$ values $(<0.80)$. These values were used to guide decision about which variable(s) from each group to include in a reduced regression model. See text for further explanation

Regression model

Auxiliary $R^{2}$

Temperature variables (with PET)

Annual range temperature $=f$ (annual min. temperature, annual max. temperature, frostfree period, PET $)+\mathrm{e}$

Annual min. temperature $=f($ annual range temperature, annual max. temperature, frostfree period, $\mathrm{PET})+\mathrm{e}$

Annual max. temperature $=f($ annual range temperature, annual min. temperature, frostfree period, $\mathrm{PET})+\mathrm{e}$

Frostfree period $=f($ annual range temperature, annual min. temperature, annual max. temperature, PET $)+\mathrm{e}$

Annual PET $=f$ (annual range temperature, annual min. temperature, annual max. temperature, frostfree period $)+\mathrm{e} \quad 0.95$

Annual PET $=f($ annual min. temperature, annual max. temperature $)+\mathrm{e}$

Temperature variables (without PET)

Annual range temperature $=f($ annual min. temperature, annual max. temperature, frostfree period $)+\mathrm{e}$

Annual min. temperature $=f$ (annual range temperature, annual max. temperature, frostfree period $)+\mathrm{e}$

Annual max. temperature $=f$ (annual range temperature, annual min. temperature, frostfree period $)+\mathrm{e}$

Frostfree period $=f($ annual range temperature, annual min. temperature, annual max. temperature $)+\mathrm{e}$

0.85

Annual min. temperature $=f($ annual max. temperature, frostfree period $)+\mathrm{e}$

0.80

Annual min. temperature $=f($ annual max. temperature $)+\mathrm{e}$

0.36

Decision: keep annual minimum temperature and annual maximum temperature,

drop annual range temperature, frostfree period, PET from temperature variables

Moisture variables (including PET)

Annual Ppt $=f($ annual AET, annual PET $)+\mathrm{e}$

Annual AET $=f($ annual Ppt, annual PET $)+\mathrm{e}$

Annual PET $=f($ annual Ppt, annual AET $)+\mathrm{e}$

0.36

Annual Ppt $=f($ annual AET $)+\mathrm{e}$

Decision: keep annual PET and annual AET or annual precipitation, not both;

but note high auxiliary $R^{2}$ of PET with temperature variables above

Topography variables

Relief $=f($ elevation $)+\mathrm{e}$

0.58

Elevation $=f($ relief $)+\mathrm{e}$

0.58

Decision: Keep both variables

$\mathrm{e}=$ error. 


\section{BIOSKETCHES}

Catherine Badgley is a research scientist at the University of Michigan and currently directs the Environmental Studies Program for the College of Literature, Arts and Sciences. Her interests include community ecology and biogeography of Cenozoic mammals, palaeoenvironmental reconstruction based on ecological attributes of mammalian faunas and the causes and consequences of the current loss of biodiversity.

David L. Fox is a postdoctoral fellow in Earth Sciences at the University of California, Santa Cruz, and will join the faculty in Geology and Geophysics at the University of Minnesota in 2001. In addition to mammalian biogeography, his research uses stable isotopes to evaluate changes in mammalian ecology from the Miocene to the Recent and simulation models to examine the role of temporal data in reconstructing phylogeny. 